NASA/TM-2008-215287

Fatigue Crack Growth Behavior

Evaluation of Grainex Mar-M 247 for NASA's

High Temperature, High Speed Turbine Seal Test Rig

Irebert R. Delgado and Bruce M. Steinetz

Glenn Research Center, Cleveland, Ohio

Clare M. Rimnac and John J. Lewandowski

Case Western Reserve University, Cleveland, Ohio 


\section{NASA STI Program . . . in Profile}

Since its founding, NASA has been dedicated to the advancement of aeronautics and space science. The NASA Scientific and Technical Information (STI) program plays a key part in helping NASA maintain this important role.

The NASA STI Program operates under the auspices of the Agency Chief Information Officer. It collects, organizes, provides for archiving, and disseminates NASA's STI. The NASA STI program provides access to the NASA Aeronautics and Space Database and its public interface, the NASA Technical Reports Server, thus providing one of the largest collections of aeronautical and space science STI in the world. Results are published in both non-NASA channels and by NASA in the NASA STI Report Series, which includes the following report types:

- TECHNICAL PUBLICATION. Reports of completed research or a major significant phase of research that present the results of NASA programs and include extensive data or theoretical analysis. Includes compilations of significant scientific and technical data and information deemed to be of continuing reference value. NASA counterpart of peer-reviewed formal professional papers but has less stringent limitations on manuscript length and extent of graphic presentations.

- TECHNICAL MEMORANDUM. Scientific and technical findings that are preliminary or of specialized interest, e.g., quick release reports, working papers, and bibliographies that contain minimal annotation. Does not contain extensive analysis.

- CONTRACTOR REPORT. Scientific and technical findings by NASA-sponsored contractors and grantees.

- CONFERENCE PUBLICATION. Collected papers from scientific and technical conferences, symposia, seminars, or other meetings sponsored or cosponsored by NASA.

- SPECIAL PUBLICATION. Scientific, technical, or historical information from NASA programs, projects, and missions, often concerned with subjects having substantial public interest.

- TECHNICAL TRANSLATION. Englishlanguage translations of foreign scientific and technical material pertinent to NASA's mission.

Specialized services also include creating custom thesauri, building customized databases, organizing and publishing research results.

For more information about the NASA STI program, see the following:

- Access the NASA STI program home page at http://www.sti.nasa.gov

- E-mail your question via the Internet to help@ sti.nasa.gov

- Fax your question to the NASA STI Help Desk at 301-621-0134

- Telephone the NASA STI Help Desk at 301-621-0390

- Write to: NASA Center for AeroSpace Information (CASI) 7115 Standard Drive Hanover, MD 21076-1320 
NASA/TM-2008-215287

Fatigue Crack Growth Behavior

Evaluation of Grainex Mar-M 247 for NASA's

High Temperature, High Speed Turbine Seal Test Rig

Irebert R. Delgado and Bruce M. Steinetz

Glenn Research Center, Cleveland, Ohio

Clare M. Rimnac and John J. Lewandowski

Case Western Reserve University, Cleveland, Ohio

National Aeronautics and

Space Administration

Glenn Research Center

Cleveland, Ohio 44135 


\section{Acknowledgments}

The authors wish to acknowledge Dr. Jack Telesman (NASA) and Mr. Pete Kantzos (Ohio Aerospace Institute) for their technical and experimental support. The authors also wish to acknowledge the NASA Glenn Fatigue and Fracture Labs, the Army Research Laboratory, and Case Western Reserve University for their support.

Trade names and trademarks are used in this report for identification only. Their usage does not constitute an official endorsement, either expressed or implied, by the National Aeronautics and Space Administration.

This work was sponsored by the Fundamental Aeronautics Program at the NASA Glenn Research Center.

Level of Review: This material has been technically reviewed by technical management.

Available from

NASA Center for Aerospace Information 7115 Standard Drive

Hanover, MD 21076-1320
National Technical Information Service 5285 Port Royal Road Springfield, VA 22161 


\title{
Fatigue Crack Growth Behavior Evaluation of Grainex Mar-M 247 for NASA's High Temperature, High Speed Turbine Seal Test Rig
}

\author{
Irebert R. Delgado and Bruce M. Steinetz \\ National Aeronautics and Space Administration \\ Glenn Research Center \\ Cleveland, Ohio 44135 \\ Clare M. Rimnac and John J. Lewandowski \\ Case Western Reserve University \\ Cleveland, Ohio 44106
}

\begin{abstract}
The fatigue crack growth behavior of Grainex Mar-M 247 is evaluated for NASA's Turbine Seal Test Facility. The facility is used to test air-to-air seals primarily for use in advanced jet engine applications. Because of extreme seal test conditions of temperature, pressure, and surface speeds, surface cracks may develop over time in the disk bolt holes. An inspection interval is developed to preclude catastrophic disk failure by using experimental fatigue crack growth data. By combining current fatigue crack growth results with previous fatigue strain-life experimental work, an inspection interval is determined for the test disk. The fatigue crack growth life of the NASA disk bolt holes is found to be 367 cycles at a crack depth of $0.501 \mathrm{~mm}$ using a factor of 2 on life at maximum operating conditions. Combining this result with previous fatigue strain-life experimental work gives a total fatigue life of 1032 cycles at a crack depth of $0.501 \mathrm{~mm}$. Eddy-current inspections are suggested starting at 665 cycles since eddy current detection thresholds are currently at $0.381 \mathrm{~mm}$. Inspection intervals are recommended every 50 cycles when operated at maximum operating conditions.
\end{abstract}

\section{Introduction}

NASA's High Temperature, High-Speed Turbine Seal Test Rig (hereafter NASA Seal Rig) (Fig. 1) tests engine seals at unique combinations of temperature, pressure, and surface speed. Because of these extreme test conditions, surface cracks may develop over operational time in the bolt holes of the Grainex Mar-M 247 disk (hereafter named GXMM247), which is used as a seal runner. If allowed to grow over time, catastrophic disk failure may occur. To preclude disk failure, periodic disk bolt hole inspections are proposed using eddy-current inspection techniques.

Eddy-current inspection is a non-destructive evaluation method used to detect cracks or flaws on component surfaces and inside turbine disk bolt holes where visual inspection techniques are not practical. Eddy-current inspection of turbine disks follows a damage tolerant philosophy widely used in the aircraft industry of detecting a flaw or crack in a component prior to it growing to critical size and causing catastrophic failure. Eddy-current inspection requires the use of a 'master flaw' sample of known dimensions to compare to readings from the actual part. The flaw would be some fraction of the critical flaw size (i.e., safety factor). Ideally, this critical flaw size is determined through compact specimen tests. However, due to a lack of available material for these specimens, surface flawed fatigue crack growth (FCG) specimens were manufactured instead to obtain corresponding FCG data. Typically, the upper portion of the FCG curve on a $d a / d N$ versus $\Delta K$ plot coincides with the critical fatigue crack growth rate which is directly related to the critical flaw size. Knowing the critical flaw size and the number of cycles to reach this flaw size, the total fatigue crack growth life of the disk bolt holes is determined. 


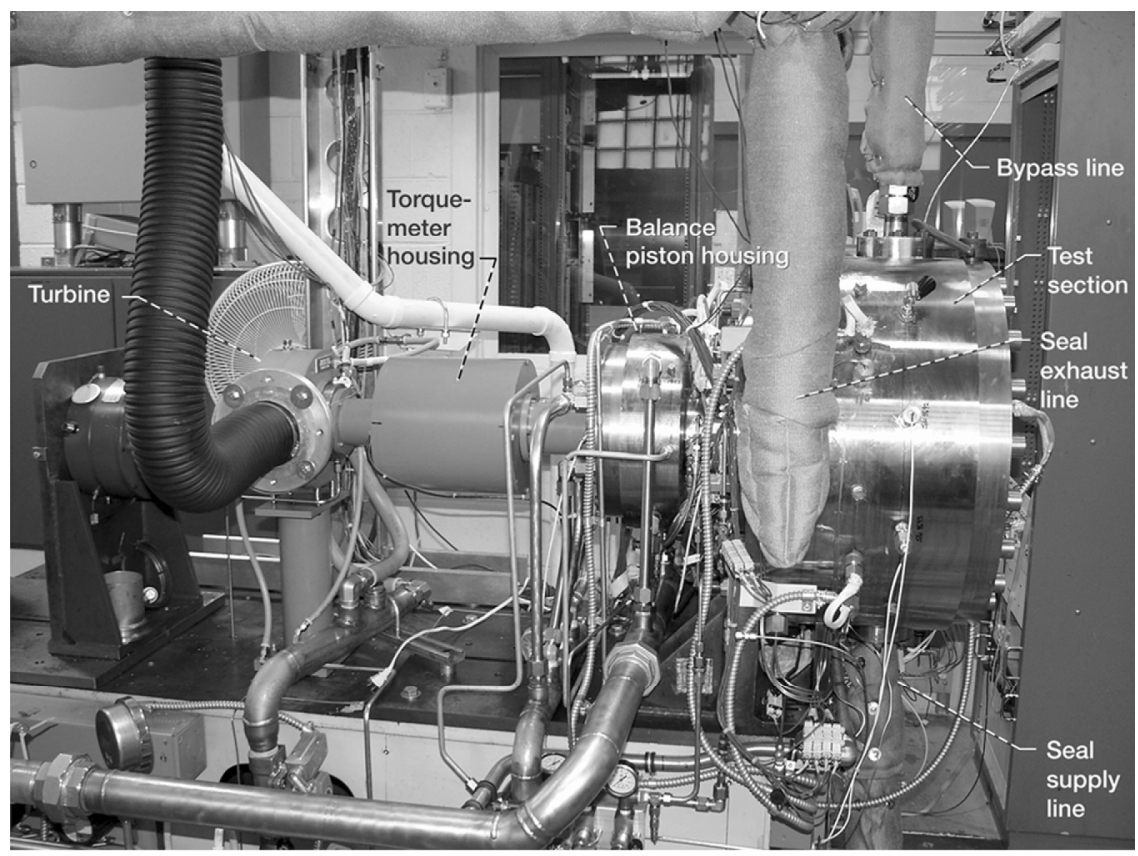

Figure 1.-NASA's Turbine Seal Test Facility.

This paper presents FCG experimental data on the GXMM247 superalloy material. Previous work by Delgado and others [1] have provided fatigue strain-life experimental results for the material. Combining these results with the current FCG experimental data would account for the total cyclic life of the disk bolt hole surfaces. Based on these results and an additional factor of safety, a corresponding eddy-current inspection interval is recommended.

\section{Material and Method-Experiment}

Fatigue crack growth tests on the GXMM247 material were at $649{ }^{\circ} \mathrm{C}$, a load ratio of $R=0.05$, and a sinusoidal waveform at a cyclic frequency of $0.33 \mathrm{~Hz}$. A surface flaw (or $K_{b}$ ) specimen (Fig. 2) was used to simulate the growth of a flaw within a disk bolt hole. The $K_{b}$ specimen was first developed by Coles et al. [2] for evaluating turbine engine components. The $K_{b}$ specimen was fabricated by electro-discharge machining (EDM) a $41 \mathrm{~mm}$ long by $14 \mathrm{~mm}$ diameter cylinder from a sacrificial GXMM247 disk (Fig. 3). The cylinders were removed at locations adjacent to the disk bolt holes and oriented perpendicular to the bolt hole axis. This oriented the machined surface flaw on the $K_{b}$ specimen perpendicular to the applied cyclic stress, since cracks tend to initiate within bolt holes from circumferential and radial disk stresses during rotation [3]. For reference, the axial direction of the disk is parallel with the bolt holes. Inconel 718 cylinders were inertia-welded to both ends of the GXMM247 cylinders and the resultant ends were machined to a buttonhead shape to allow the fatigue testing machine to grip the specimen. Then, the GXMM247 portion of the specimen was machined to transition from a cylindrical shaped cross-section at the Inconel 718/GXMM247 interface to a rectangular cross-section at the specimen center or gage section. Finally, a surface flaw was plunge EDM'd on one side of the rectangular gage section in the shape of half a circular disk (Fig. 4). The initial depth and width of the surface flaw were approximately half of those dimensions shown in Fig. 4 after failures outside the gage section occurred in preliminary tests. Thus, the final surface flaw size used was $0.46 \mathrm{~mm}$ in depth by $0.91 \mathrm{~mm}$ in width. This EDM notch enlargement was necessary to encourage crack growth at the surface flaw. All FCG specimens (Fig. 5) were fabricated at Mar-Test in Cincinnati, Ohio.

FCG tests were performed at the NASA Glenn Research Center fatigue and fracture laboratories. A Materials Test System 810 (MTS Corporation, Minneapolis, Minnesota) was utilized (Fig. 6). The system 
is computer-controlled by a custom program, MATE (Material Analysis and Test Environment), which also acquires the raw FCG data [4]. Crack length computations for the $K_{b}$ specimen are based on a closedform analytical model by Gangloff et al. that has been experimentally confirmed [5-7]. FCG of the $K_{b}$ specimen was measured using the direct current electrical potential difference (dcEPD) method. The method was initially developed by Gangloff [8] for small surface cracks in hour-glass shaped specimens. The method was modified by Vanstone and Richardson [9] for specimens having rectangular cross sections with semi-circular EDM notches. FCG in a semi-circular crack is related to voltage through an analytical model developed by Roe and Coffin. This is referenced in Gangloff [8]. To facilitate potential drop measurements, $0.13 \mathrm{~mm}$ diameter Alumel wires were tack-welded to either side of the EDM notch (Fig. 7).
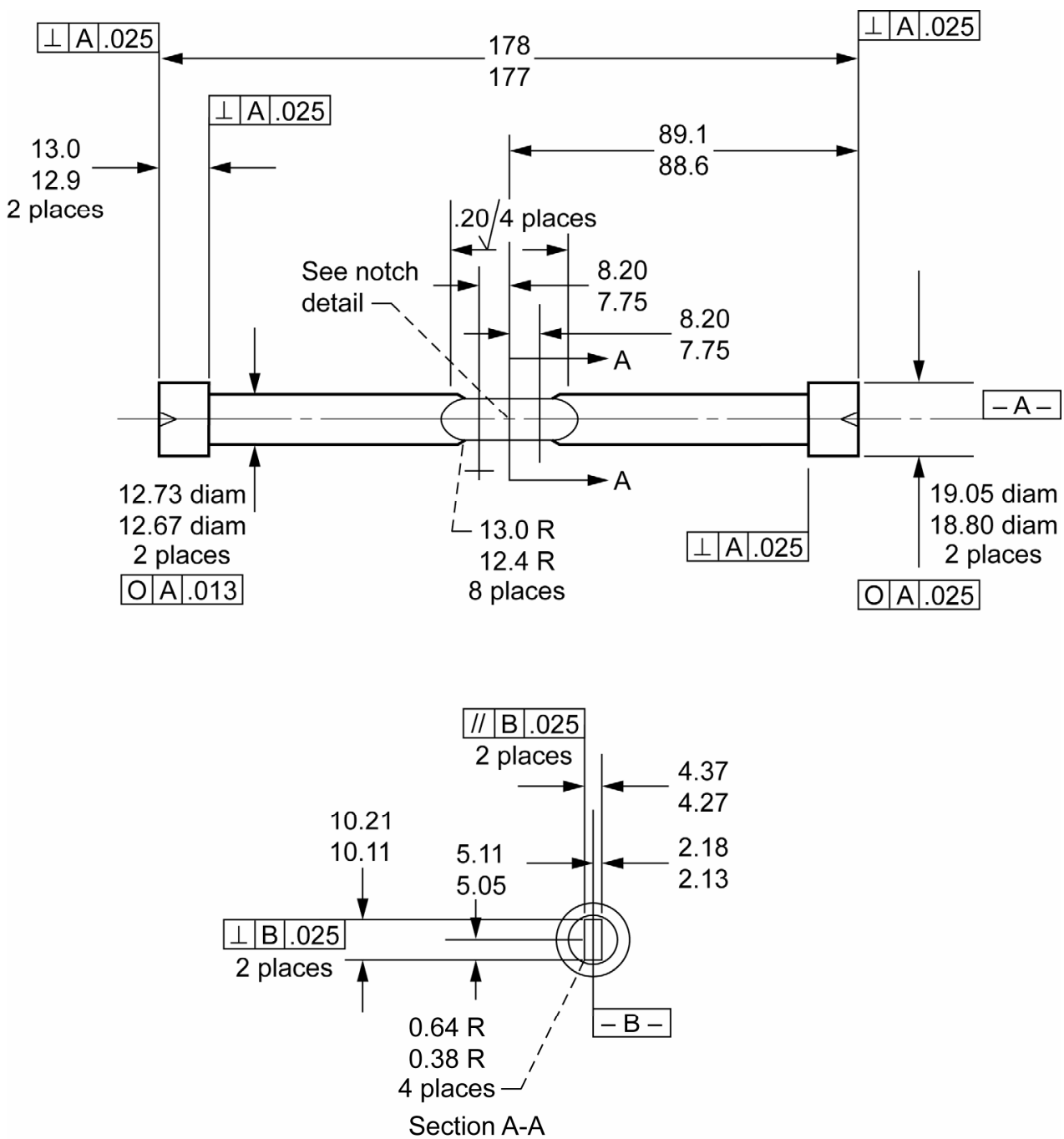

Figure 2.-Surface flaw $\left(K_{b}\right)$ specimen geometry for the GXMM247 fatigue crack growth tests at $649^{\circ} \mathrm{C}$. Dimensions are in millimeters. 

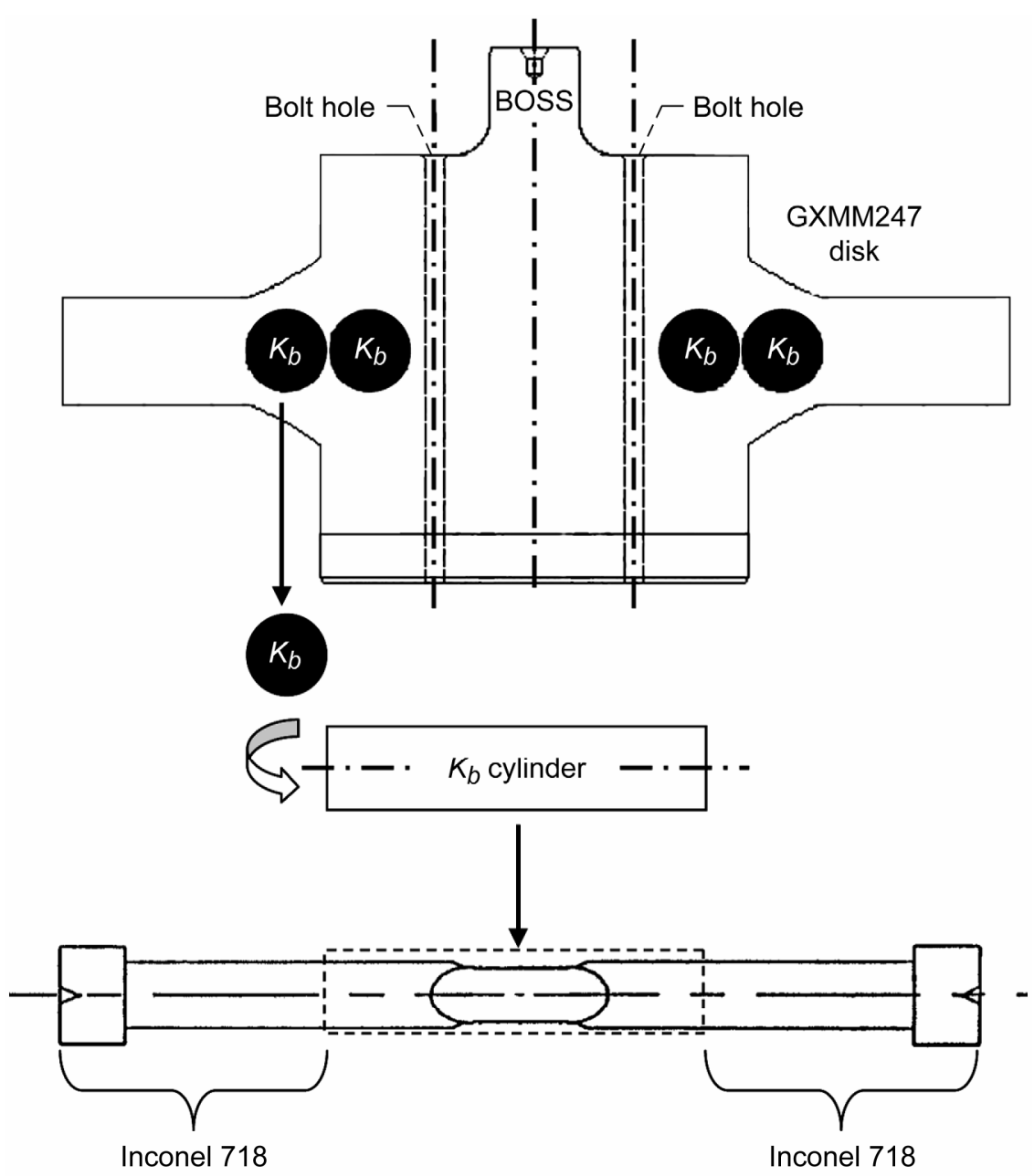

Figure 3.-Location of fatigue crack-growth $K_{b}$ specimens from sacrifical GXMM247 disk.

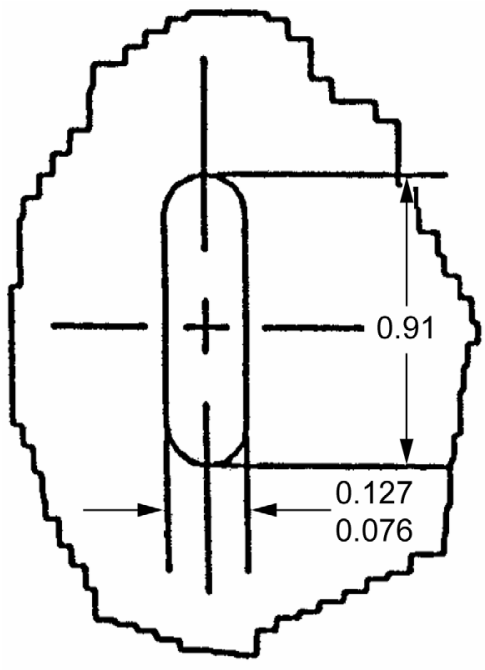

Notch detail

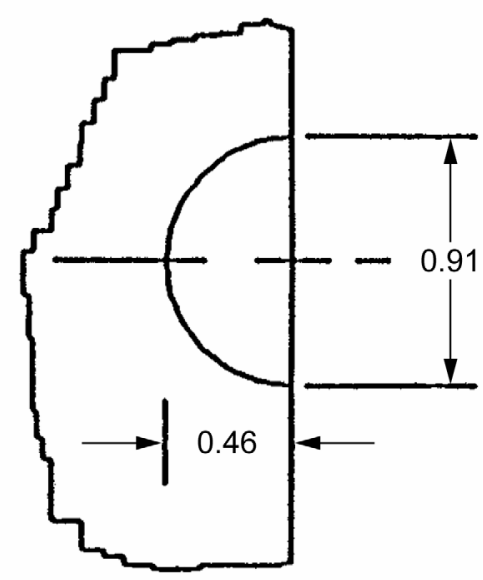

Notch detail (view section A-A)

Figure 4.-Surface flaw geometry for the $\left(K_{b}\right)$ specimen. Dimensions are in millimeters. See Fig. 2 for notch location on $\left(K_{b}\right)$ specimen. 


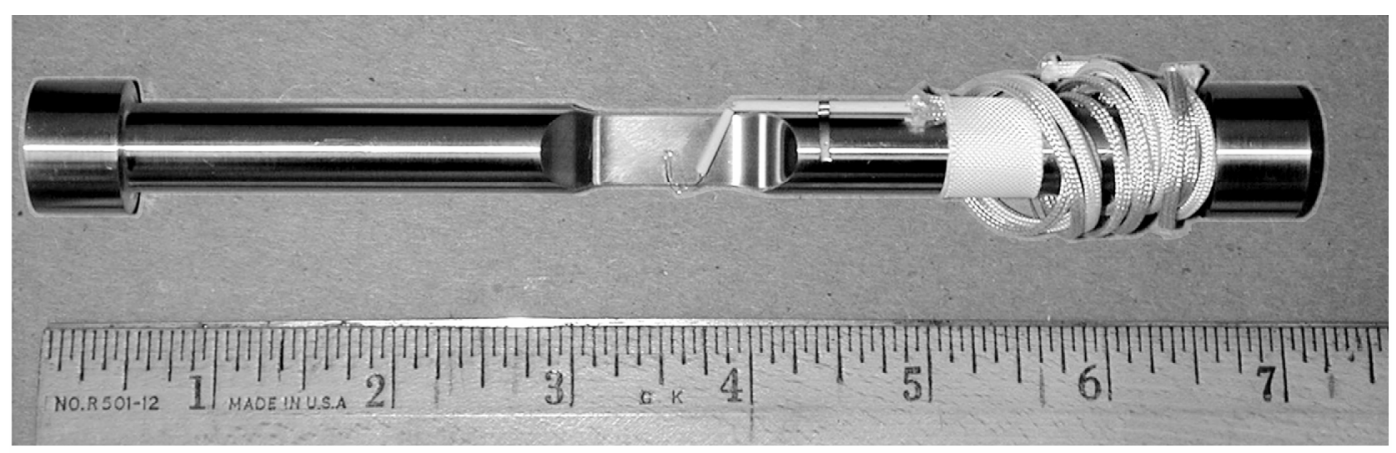

Figure 5.- $K_{b}$ specimen with alumel wire attachments for potential drop crack growth measurement.
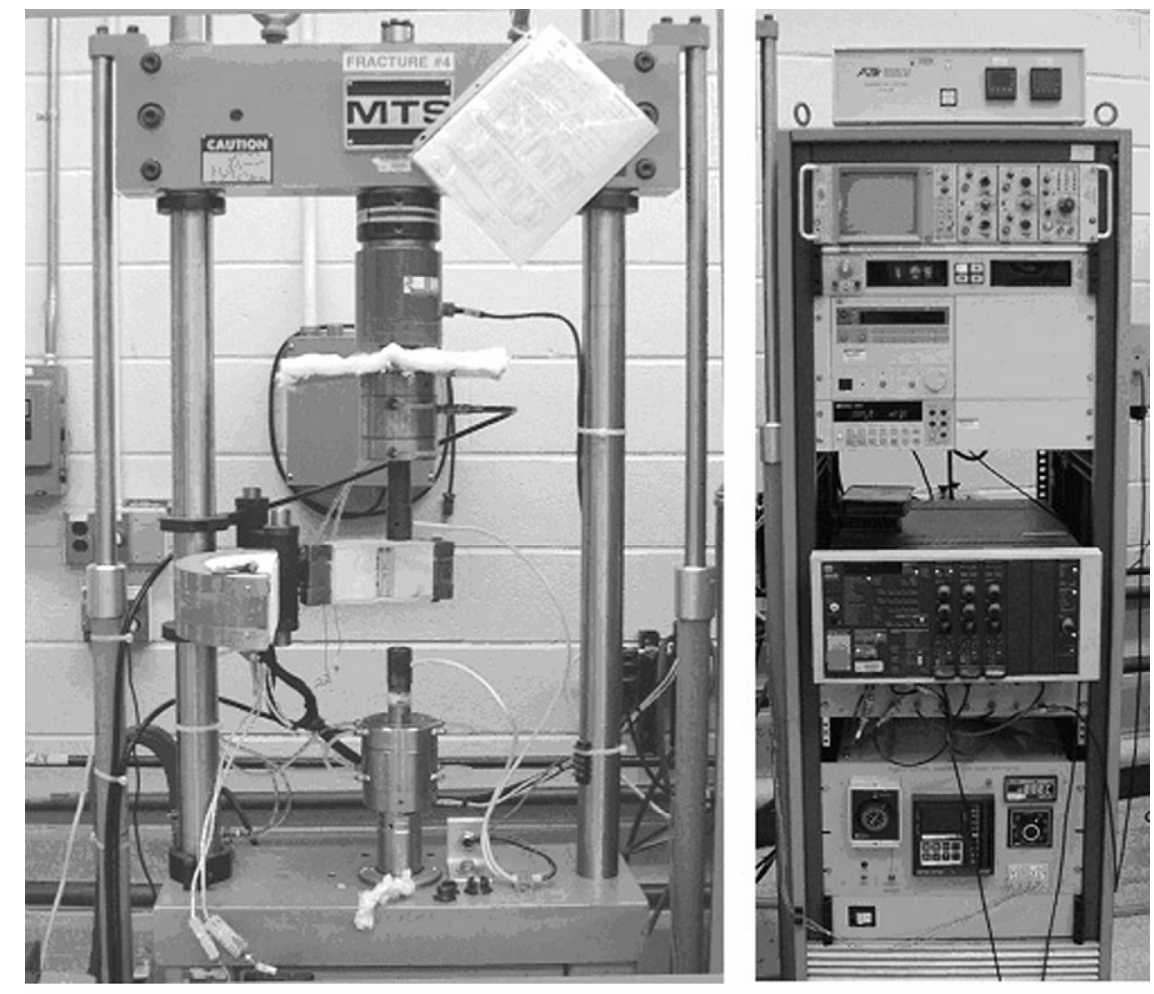

Figure 6.-Fatigue crack growth test equipment and controls at NASA's fatigue and fracture laboratories.
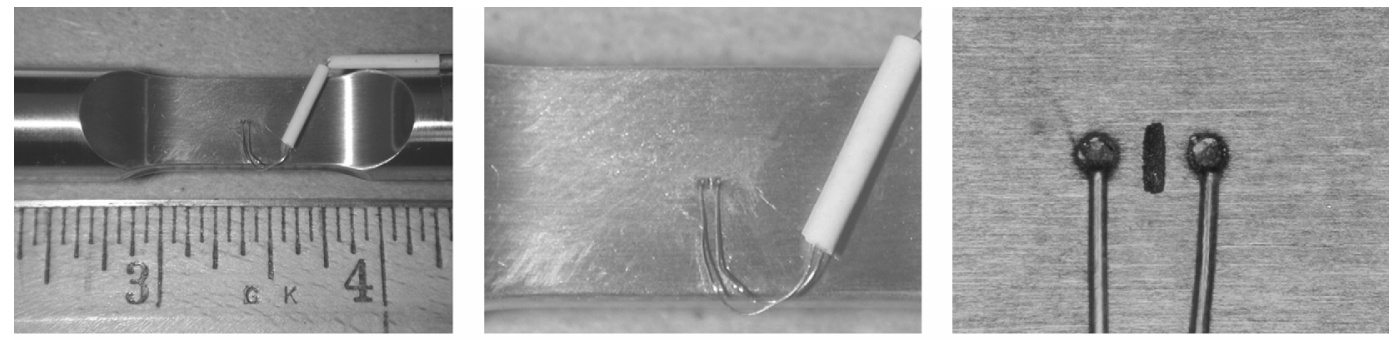

Figure 7.-Alumel wire location at the notch area of the $K_{b}$ specimen. 


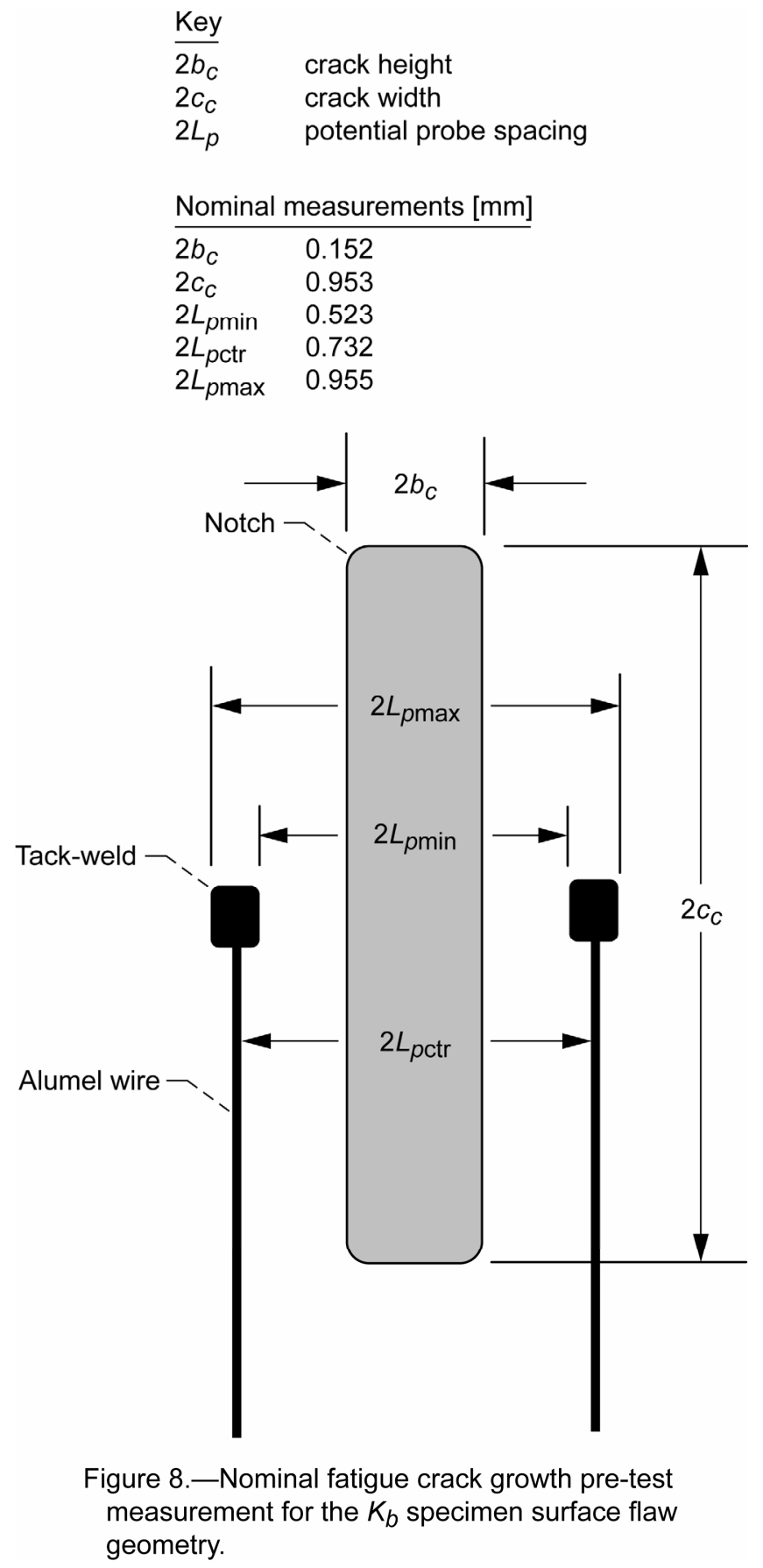

Measurements of the EDM notch geometry (Fig. 8) were taken prior to installing the $K_{b}$ specimen in the load frame. The measurements included the notch height, width, and depth as well as the potential probe spacing. Measurements were taken with a Nikon Measurescope 10 (Nikon, Tokyo, Japan) and a Nikon SC-102 X-Y digital readout (Nikon, Tokyo, Japan). The Measurescope has an accuracy of \pm 0.0025 $\mathrm{mm}$. The measurements were used as inputs into MATE to calculate crack length, maximum load, and dcEPD voltage during the test. An assumption on the EDM crack depth was initially inputted into MATE, based on original EDM notch specifications, and was subsequently corrected during post-test calculations. 
The $K_{b}$ specimen was installed into the MTS load frame with 12-gage copper leads attached to the buttonheads. A constant $10 \mathrm{~A}$ was applied to the leads, forming a circuit through the specimen and resulting in a potential drop across the Alumel wire locations (Fig. 7) which increases with increasing crack length and depth. Baseline voltage measurements were taken to adjust for thermoelectric influences [10]. Prior to starting the pre-cracking portion of the test, initial voltages were taken at $0 \mathrm{~N}$ and $17.8 \mathrm{KN}$ axial load on the $K_{b}$ specimen. The specimen was precracked at room temperature with a sinusoidal waveform at $3 \mathrm{~Hz}$, and $R=0.05\left(P_{\max }=25.8 \mathrm{KN}\right)$ and grown to a depth of approximately $0.81 \mathrm{~mm}$. Precracking was conducted to ensure that FCG occurred beyond the recast layer resulting from the EDM notch. Both crack length voltages and number of cycles were acquired. After precracking, reference voltage measurements $\left(V_{N}\right)$ were again taken at $0 \mathrm{~N}$ and $17.8 \mathrm{KN}$ axial load. These voltages were used to correct for voltage drift and for normalizing the acquired crack length voltages for data reduction. Reference voltages were taken prior to the pre-crack test and the actual crack-growth test at $649{ }^{\circ} \mathrm{C}$.

Three type-K thermocouples were tack-welded to the gage section of the $K_{b}$ specimen (Fig. 9). Thermocouple 1 (T/C 1) measured the $K_{b}$ specimen test temperature and was centered in the middle of the gage section. T/C 2 and T/C 3 controlled the specimen temperature and were spaced $6.35 \mathrm{~mm}$ on either side of the center thermocouple. Two half-section resistance furnaces (Fig. 6) were then positioned around the $K_{b}$ specimen. The specimen was heated to $649 \pm 1{ }^{\circ} \mathrm{C}$ at zero load with the $K_{b}$ surface temperature read-out through a digital meter. Initial voltage potentials were measured at axial loads of $0 \mathrm{~N}$ and $17.8 \mathrm{KN}$. An initial voltage was also taken to account for thermoelectric influences. The test was conducted with a sinusoidal waveform at $0.33 \mathrm{~Hz}$, and a ratio of $R=0.05\left(P_{\max }=27.4 \mathrm{KN}\right)$. For each acquisition, MATE recorded the cycle count, total crack length, maximum load, corrected dcEPD voltage, number of dcEPD points acquired, thermoelectrically induced voltage, and input load ratio. Data was taken approximately every $0.0508 \mathrm{~mm}$ of crack extension [11]. The crack was allowed to grow to $2.54 \mathrm{~mm}$. This crack length limitation was due to the $4.32 \mathrm{~mm}$ gage thickness. Experience has shown that crack length voltage accuracy begins to drop off for crack lengths at approximately $65 \%$ of the gage thickness [12]. Final voltages were again taken at axial loads of $0 \mathrm{~N}$ and $17.8 \mathrm{KN}$. After the $2.54 \mathrm{~mm}$ crack depth was attained, the test specimen was fractured by monotonically increasing the load to specimen failure.

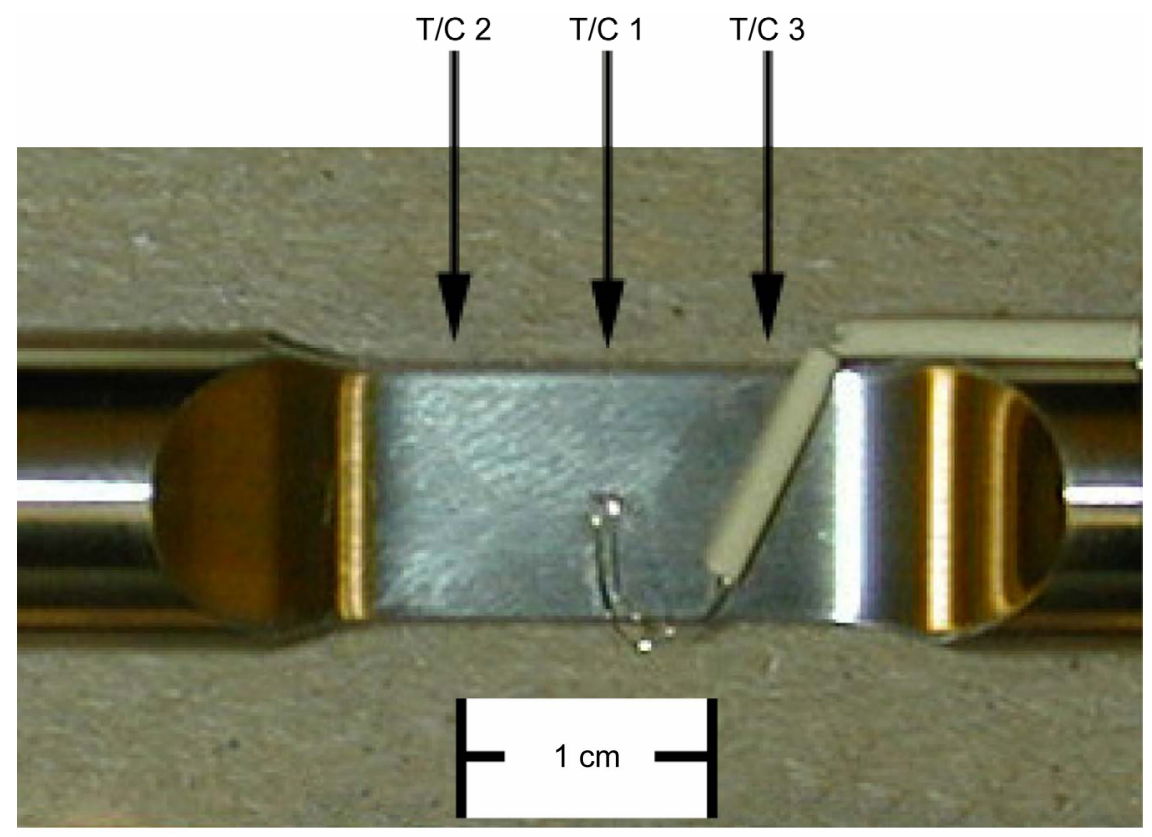

Figure 9.-Thermocouple locations on the $K_{b}$ specimen gage section indicated by the arrows. Thermocouples not shown. 


\section{Data Reduction-Fatigue Crack Growth Rate}

FCG data are reduced to a Paris type relationship [13] where the FCG rate, $d a_{c} / d N$, is related to the stress intensity factor, $\Delta K$ :

$$
\frac{d a_{c}}{d N}=C(\Delta K)^{m}
$$

As mentioned previously, crack depth data were corrected based on post-test measurements of the fracture surface (Figs. 10 and 11). These measurements were inputted into MATE. Crack depth and length per cycle were calculated iteratively within MATE which compares the measured voltage for a calculated crack depth to the voltage predicted by the Roe-Coffin potential solution [9] for a semielliptical surface notch. The Roe-Coffin solution, given by Gangloff [8], has the form

$$
V / V_{N}=f\left(a_{c}, b_{c}, c_{c}, a_{n}, b_{n}, c_{n}, L_{p}\right)
$$

The crack depth and length were iterated within MATE such that the difference between the measured and predicted voltages of the crack depth and length were minimized. This was done by holding constant $V / V_{N}, a_{n}, b_{n}, c_{n}$, and $L_{p}$, and holding constant the aspect ratio, $c_{c} / a_{c}$, for each increment of crack depth acquired during the test. The procedure was identical for crack length.

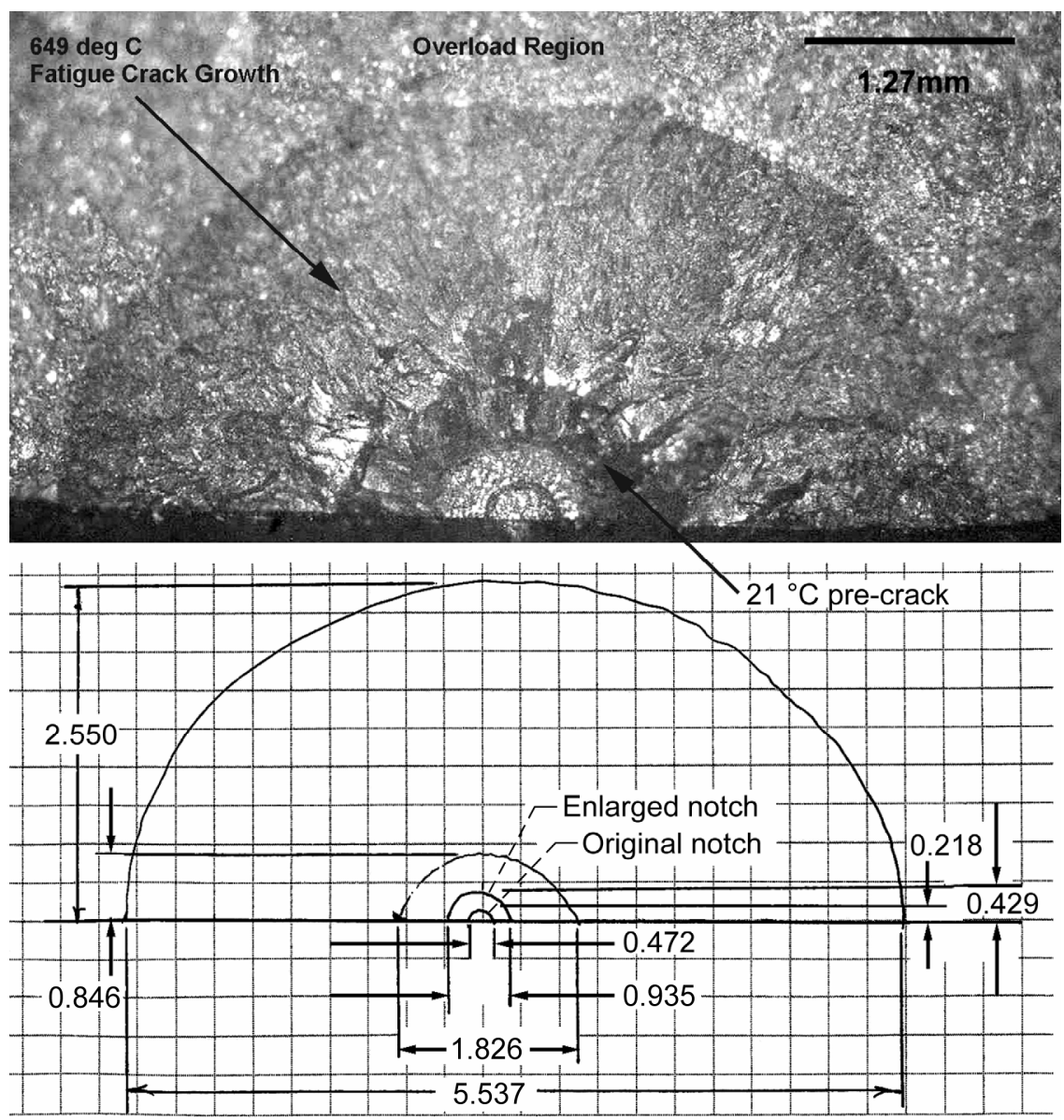

Figure 10.-Fracture surface measurements for the GXMM247

$\left(K_{b}\right.$ specimen $\left.13 \mathrm{~K}\right)$. Dimensions are in millimeters. 


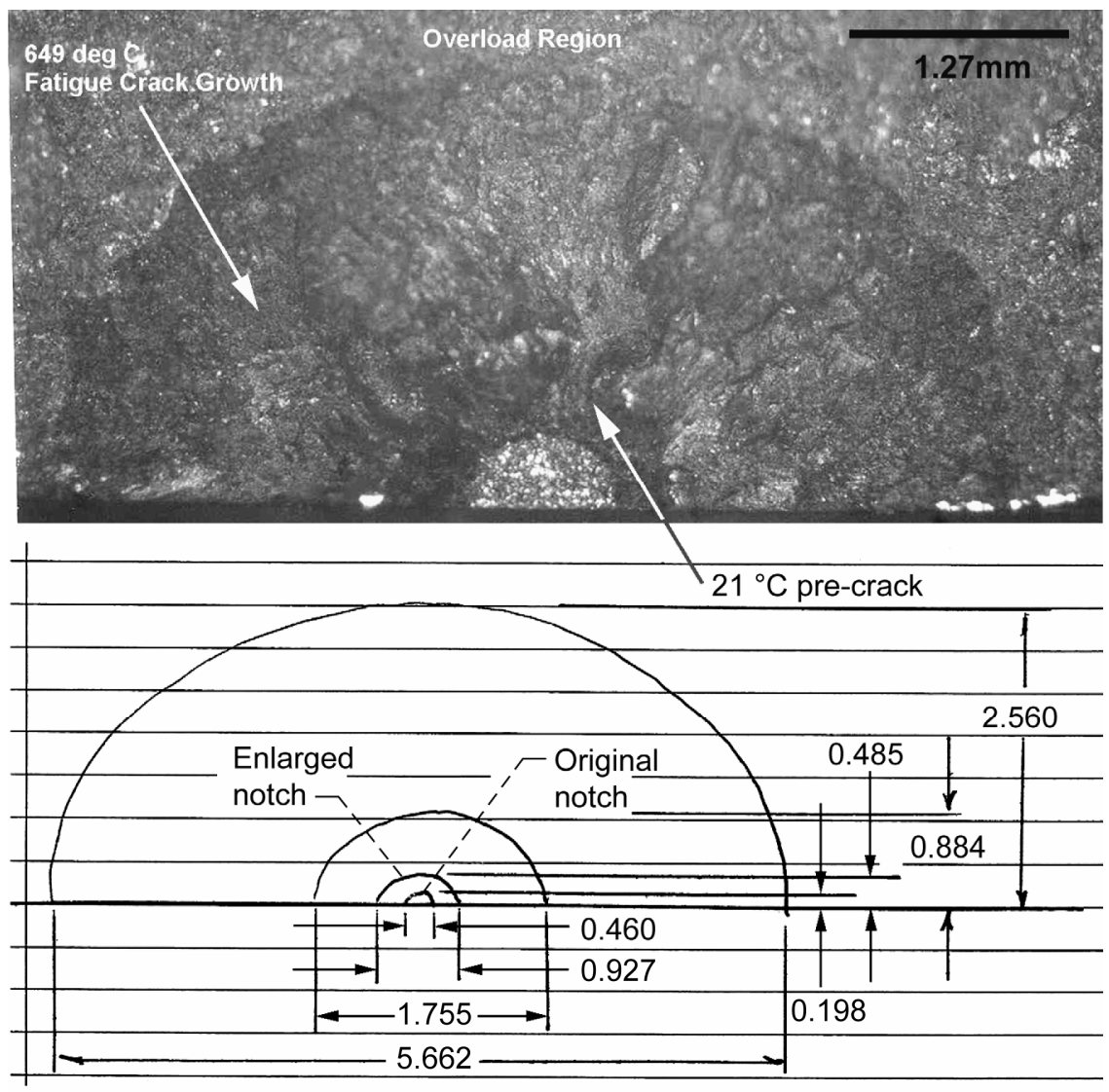

Figure 11.-Fracture surface measurements for the GXMM247 $\left(K_{b}\right.$ specimen $\left.32 \mathrm{~K}\right)$. Dimensions are in millimeters.

The fatigue crack growth rate, $d a_{c} / d N$, was calculated using the incremental polynomial method, per ASTM E647 [14]. The stress intensity range, $\Delta K$, was calculated within MATE using stress-intensity factor equations developed by Newman and Raju [13] for a semi-elliptical surface crack subjected to tensile loading:

$$
K_{I}=s \sqrt{\pi \frac{a_{c}}{Q} F_{s}\left(\frac{a_{c}}{c_{c}}, \frac{a_{c}}{t}, \frac{c_{c}}{b_{c}}, \phi\right)}
$$

The maximum stress intensity factor, $K_{\max }$, was determined by inputting the maximum recorded load at each data point into Eq. (2), which is programmed into MATE. Finally, $\Delta K$ [15] was calculated using

$$
\Delta K=K_{\max }(1-R)
$$

The resultant $d a_{c} / d N$ versus $\Delta K$ data were then plotted on log-log coordinates.

\section{Data Reduction-Statistics}

Linear regression analysis was conducted to evaluate the log-log transformed data:

$$
\log \left(\frac{d a_{c}}{d N}\right)=\log (C)+m \log (\Delta K)
$$


A statistical comparison between regression lines was performed to determine if the individual slopes and intercepts were statistically similar at a confidence level of $95 \%$. If this were true, then resultant data sets from individual tests could be combined to provide a statistically stronger relationship between fatigue crack growth rate and stress intensity range. A test of equal variances on the error terms for each regression line was first done to validate a comparison between regression lines [16]. To test for similar slopes and intercepts, a reduced statistical model was determined which combined data sets from successful FCG tests. The reduced statistical model was:

$$
Y_{i j}=\beta_{0}+\beta_{1} X_{i j}+\varepsilon_{i j}
$$

A test statistic [16], $F^{*}$, was calculated and compared with the $F$ value determined from $F$-tables based on a predetermined significance level $(0.10)$ and degrees of freedom $(120) . F^{*}$ is defined as:

$$
F^{*}=\frac{S S E(R)-S S E(F)}{2} \div \frac{S S E(F)}{n_{1}+n_{2}-4}
$$

For $F^{*} \leq F\left(1-a ; 2, n_{1}+n_{2}-4\right)$ a conclusion can be made that the slopes and intercepts of both regression lines are equal. Note that "a" is the desired percentile level.

\section{FCG Behavior Considerations}

Limitations on crack behavior were considered in large part due to the relatively coarse grain structure of the GXMM247 material. To validate the linear-elastic fracture mechanics (LEFM) approach, evaluations were made on small-crack behavior, specimen geometry with respect to grain size, and plastic-zone size with respect to grain size.

\section{Small Crack Growth Behavior}

Because of the small size of the EDM notch dimensions (Fig. 4) with respect to the GXMM247 grain size of $1.6 \mathrm{~mm}$ [17], it was possible that FCG would occur in the small crack growth regime. Small cracks are defined as having dimensions equal to or smaller than the dimension of greatest microstructural significance, such as grain size [15]. Small cracks are characterized by higher growth rates and their ability to grow at $\Delta K$ values below the threshold stress intensity range, $\Delta K_{\text {th. }}$.[18] Small cracks may decelerate and arrest or approach a minimum in FCG rate, then accelerate, and merge with long crack growth behavior. Thus, the FCG behavior and respective crack size relative to the grain size were evaluated to determine if FCG followed small crack behavior.

\section{Linear-Elastic Fracture Mechanics}

An assessment of the validity of LEFM was made based on specimen geometry. The surface-flawed specimen geometry was considered due to the lack of available GXMM247 material. LEFM [15]

limitations were compared to specimen geometry based on

$$
a_{c},\left(t-a_{c}\right), h \geq \frac{4}{\pi}\left(\frac{K_{\max }}{\sigma_{y(0.2 \%)}}\right)^{2}
$$

\section{Plastic-Zone Size}

The plastic zone size was compared with the average grain size of GXMM247. Ideally, the plastic zone should carry a number of grains within the material such that the FCG behavior is microstructurallyinsensitive. The plastic zone size for plane stress conditions [15], $2 r_{0 \sigma}$, was estimated by: 


$$
2 r_{0 \sigma}=\frac{1}{\pi}\left(\frac{K_{\max }}{\sigma_{y(0.2 \%)}}\right)^{2}
$$

\section{Fractographic Examination}

Fractographic examination of the fracture surfaces was performed to identify grain boundaries that may affect FCG and to determine if fatigue striations were a good indicator of cyclic stress intensity.

Fatigue crack propagation surfaces from each specimen were prepared for examination by carefully removing the gage section with a cut-off wheel. The surface was cleaned and then mounted. Fracture surfaces were examined using a light microscope and a scanning electron microscope (SEM) under secondary electron (SE) and backscattered electron (BE) modes.

Fracture surface features were identified including: initial and final EDM notches; precrack region; low $\Delta K(=23.3$ to $26.4 \mathrm{MPa} \sqrt{m})$ and high $\Delta K(=35.7$ to $39.1 \mathrm{MPa} \sqrt{m})$ regions; and the overload region. SEM micrographs of the low and high $\Delta K$ regions were taken, respectively, at 1.00 to $1.25 \mathrm{~mm}$ and 2.00 to $2.25 \mathrm{~mm}$ from the EDM notch origin. A comparison was made between crack growth rate and crack depth. The microscopic crack growth rate was determined for the low and high $\Delta K$ regions by measurement of striation spacings.

A comparison was made between the experimentally applied $\Delta K$ and the calculated $\Delta K$ based on striation spacings at the low and high $\Delta K$ fracture surface regions using the Bates and Clark relationship [19]:

$$
\text { striation spacing }=6\left(\frac{\Delta K}{E}\right)^{2}
$$

where Young's modulus, $E$, was taken to be $194 \mathrm{GPa}$ (see [1]). The experimental $\Delta K$ used to compare with the Bates and Clark relationship was taken from the averaged $\Delta K$ determined from the low $\Delta K$ regime $(24.85 \mathrm{MPa} \sqrt{m})$ and high $\Delta K$ regime $(37.40 \mathrm{MPa} \sqrt{m})$.

\section{Results and Discussion}

\section{Test Summary}

Of the original eight $K_{b}$ specimens, two tests (using specimens identified as $13 \mathrm{~K}$ and $32 \mathrm{~K}$ ) were successfully conducted after doubling the EDM notch width and depth. Four $K_{b}$ specimens, previously tested, failed prematurely outside the EDM notch. The remaining two were untested. Hereafter, the results pertain only to $K_{b}$ specimens $13 \mathrm{~K}$ and $32 \mathrm{~K}$.

\section{Experimental Data}

The FCG behavior for the two tests specimens is shown in Figs. 12 and 13 with the coefficient, $C$, and exponent, $m$, from Eq. (1) given for each specimen in Table 1.

TABLE 1.-LINEAR REGRESSION RESULTS FOR FATIGUE CRACK GROWTH BEHAVIOR OF GXMM247 $K_{b}$ SPECIMENS (13K AND 32K) AT $649{ }^{\circ} \mathrm{C}$ FOR THE ENTIRE STRESS INTENSITY RANGE TESTED.

\begin{tabular}{|c|c|c|c|c|c|}
\hline $\begin{array}{c}\text { Specimen, } \\
\mathrm{K}\end{array}$ & Intercept & Slope & $\mathrm{R}^{2}$ & $\begin{array}{c}\text { Constant, } \\
C\end{array}$ & $\begin{array}{c}\text { Exponent, } \\
m\end{array}$ \\
\hline $13 \mathrm{~K}$ & -11.98 & 5.80 & 0.93 & $1.05 \times 10^{-12}$ & 5.80 \\
\hline $32 \mathrm{~K}$ & -10.53 & 4.82 & 0.90 & $2.94 \times 10^{-11}$ & 4.82 \\
\hline
\end{tabular}




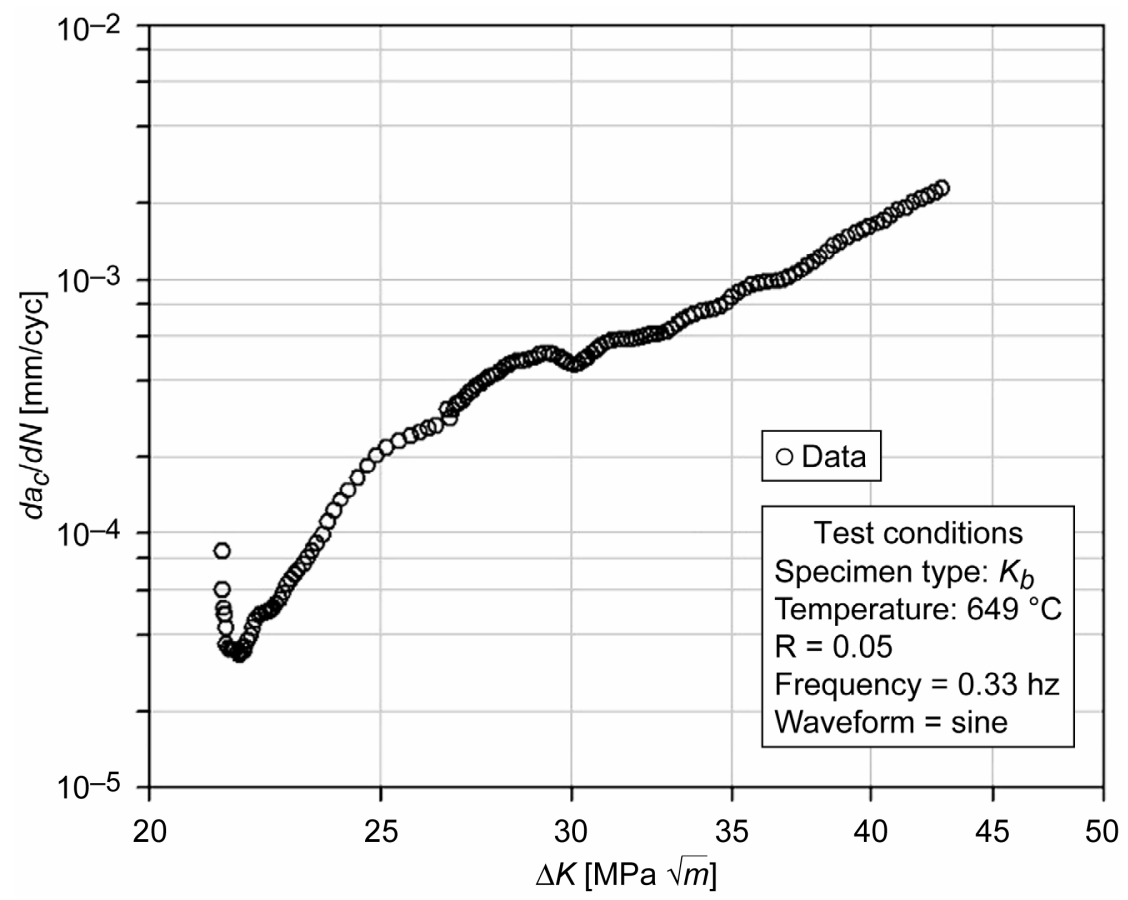

Figure 12.-Fatigue crack growth behavior for GXMM247 at $649{ }^{\circ} \mathrm{C}$ $\left(K_{b}\right.$ specimen $\left.13 \mathrm{~K}\right)$.

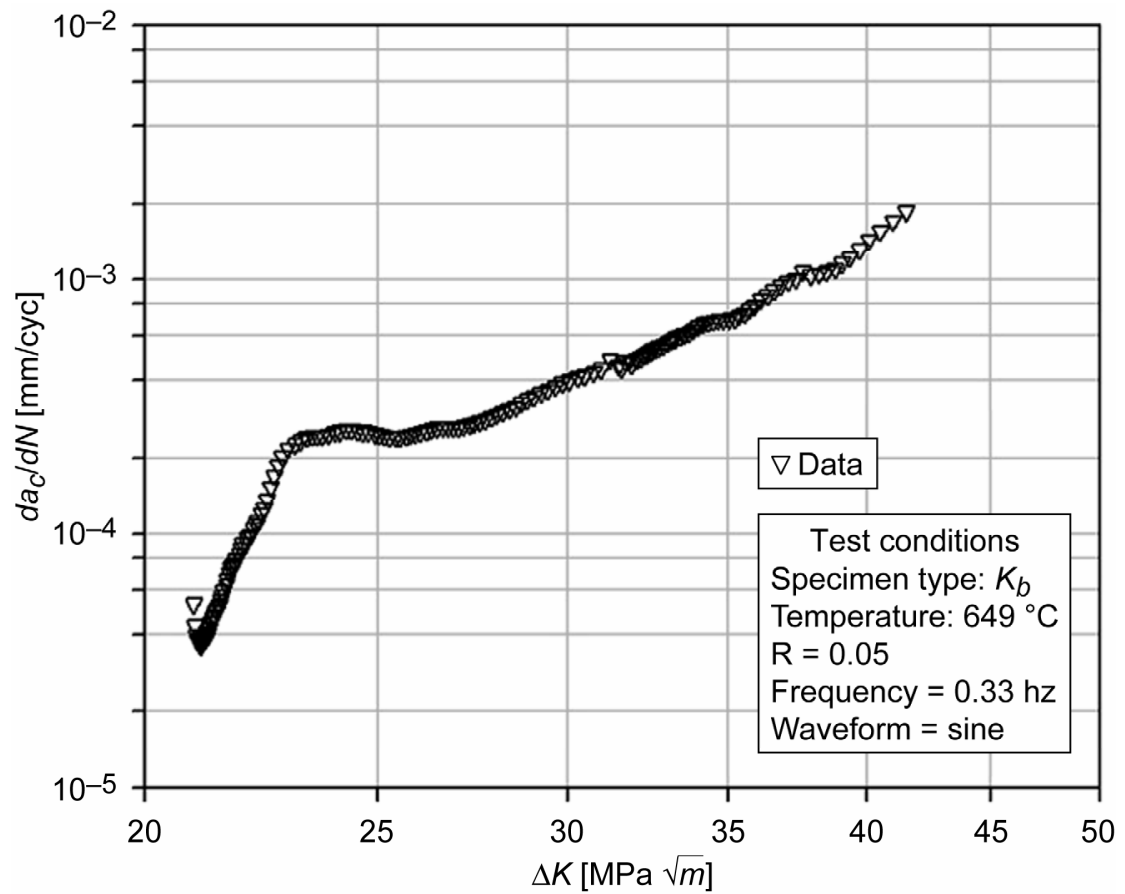

Figure 13.-Fatigue crack growth behavior for GXMM247 at $649{ }^{\circ} \mathrm{C}$ $\left(K_{b}\right.$ specimen $\left.32 K\right)$.

The deceleration and then acceleration of the $d a_{c} / d N$ data in the low $\Delta K$ region may be due to the crack approaching microstructural barriers such as grain boundaries or due to crack closure $[18,20]$. This small crack growth behavior generally transitions into long crack growth behavior at higher $\Delta K$ values [21], and this appears to have been the case in this study. 


\section{Statistics}

FCG data with regressions from both data sets were analyzed for similarity. The variances between the individual regressions were found to be equivalent to a $95 \%$ confidence level. Thus a comparison between the regressions for similarity was valid. The reduced model Eq. (6) was determined with $\beta_{0}=-11.20$ and $\beta_{1}=5.28$. Finally, $F^{*}$ from Eq. (7) was calculated as -72.56 . From standard $F$-tables, $F(0.999,2,120)$ was 7.32 . Thus $F^{*} \leq F$ and the slopes and intercepts were equal to within a $99.9 \%$ confidence level. The data from the two specimens were thus combined into one data set and an overall coefficient, $C$, and exponent, $m$, were determined (Fig. 14).

To be conservative in predicting FCG life, both data sets $(13 \mathrm{~K}$ and $32 \mathrm{~K})$ were used with regression analysis over the entire experimentally determined range. The steeper $d a_{c} / d N$ versus $\Delta K$ slope in both data sets at low $\Delta K$ was thus taken into account as well as the shallower slope at high $\Delta K$.

\section{FCG Behavior Considerations}

\section{Small Crack Growth Behavior}

Small crack growth behavior was observed for both FCG specimens (Figs. 12 and 13). That is, the crack growth rate for both specimens was observed to initially decelerate to a minima and then to transition into the long crack growth regime where more uniform FCG behavior is expected.

In this study, the transition from small crack growth to long crack growth appeared to occur at approximately $\Delta K=30 \mathrm{MPa} \sqrt{m}\left(d a_{c} / d N=4 \times 10^{-4} \mathrm{~mm} /\right.$ cycle) for both FCG tests (Fig. 14), based on the similarity in $d a_{c} / d N$ versus $\Delta K$ behavior above the transition. Consistent with this, the corresponding range of crack depths at that stress intensity was between 1.55 and $1.65 \mathrm{~mm}$ (Fig. 15). This coincides with reported GXMM247 average grain sizes of $1.6 \mathrm{~mm}$. In other words, once the crack grows larger than the grain size, long crack growth behavior is expected.

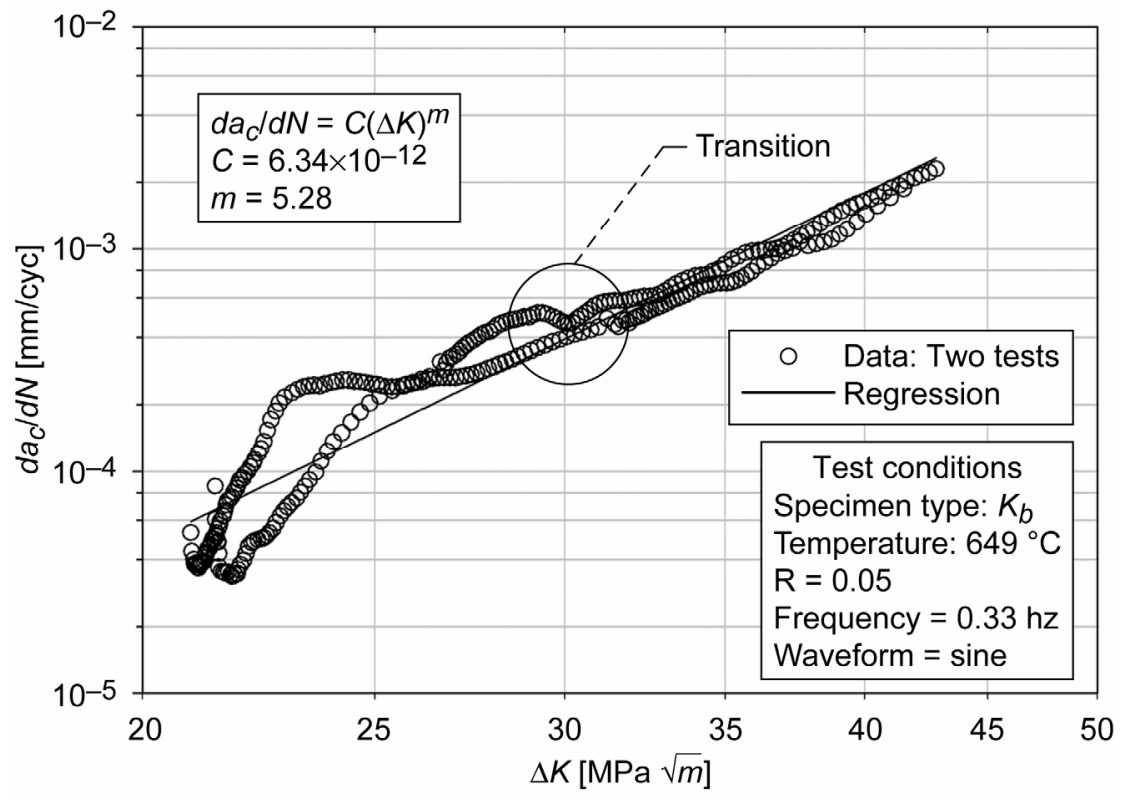

Figure 14.-Regression results using both specimen data sets for GXMM247 fatigue crack growth $K_{b}$ data. 


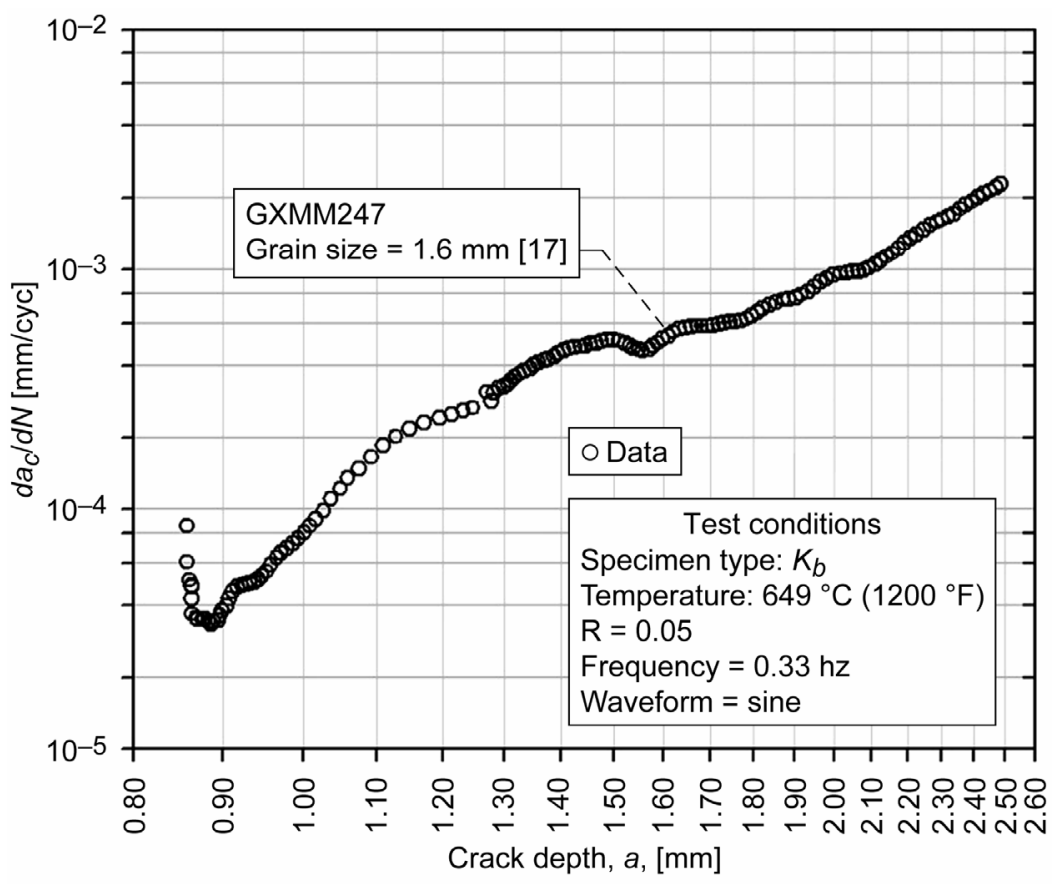

Figure 15.-Fatigue crack growth rate versus crack depth for GXMM247 at $649^{\circ} \mathrm{C}\left(K_{b}\right.$ specimen $\left.13 \mathrm{~K}\right)$.

\section{Linear Elastic Fracture Mechanics}

Initial and final crack lengths for both FCG test specimens were compared to the $K_{b}$ specimen geometry to determine LEFM applicability using Eq. (8), (table 2). Initial crack lengths did not meet LEFM criteria for either specimen. Final crack lengths and remaining gage specimen thickness (i.e., $t-a_{c}$ ) also did not meet LEFM criteria.

TABLE 2.-COMPARISON OF INITIAL AND FINAL CRACK LENGTHS OF $K_{b}$ SPECIMENS (13K AND 32K) WITH LEFM APPLICABILITY AT $649^{\circ} \mathrm{C}$.

\begin{tabular}{|c|c|c|c|c|c|c|c|}
\hline $\begin{array}{c}\text { Initial, } \\
\mathrm{mm}\end{array}$ & $13 \mathrm{~K}$ & $\begin{array}{c}13 \mathrm{~K} \\
\text { criteria }\end{array}$ & $\begin{array}{c}\text { Pass/ } \\
\text { Fail }\end{array}$ & $\begin{array}{c}\text { Initial, } \\
\mathrm{mm}\end{array}$ & $32 \mathrm{~K}$ & $\begin{array}{c}32 \mathrm{~K} \\
\text { criteria }\end{array}$ & $\begin{array}{c}\text { Pass/ } \\
\text { Fail }\end{array}$ \\
\hline$a_{c}$ & 0.846 & 0.963 & Fail & $a_{c}$ & 0.884 & 0.919 & Fail \\
\hline$\left(t-a_{c}\right)$ & 3.472 & 0.963 & Pass & $\left(t-a_{c}\right)$ & 3.434 & 0.919 & Pass \\
\hline $\mathrm{h}$ & 7.976 & 0.963 & Pass & $H$ & 7.976 & 0.919 & Pass \\
\hline $\begin{array}{c}\text { Final, } \\
\mathrm{mm}\end{array}$ & $13 \mathrm{~K}$ & $\begin{array}{c}13 \mathrm{~K} \\
\text { criteria }\end{array}$ & $\begin{array}{c}\text { Pass/ } \\
\text { Fail }\end{array}$ & $\begin{array}{c}\text { Final, } \\
\mathrm{mm}\end{array}$ & $32 \mathrm{~K}$ & $\begin{array}{c}32 \mathrm{~K} \\
\text { criteria }\end{array}$ & $\begin{array}{c}\text { Pass/ } \\
\text { Fail }\end{array}$ \\
\hline$a_{c}$ & 2.550 & 3.840 & Fail & $a_{c}$ & 2.560 & 3.607 & Fail \\
\hline$\left(t-a_{c}\right)$ & 1.768 & 3.840 & Fail & $\left(t-a_{c}\right)$ & 1.758 & 3.607 & Fail \\
\hline$h$ & 7.976 & 3.840 & Pass & $h$ & 7.976 & 3.607 & Pass \\
\hline
\end{tabular}

The use of an LEFM approach for FCG tests assumes that plasticity is limited to a local region that is small compared to the specimen dimensions [15]. Predicted gross yielding of the specimen makes the use of an LEFM approach questionable. In this study, during FCG testing, the initial maximum stress level at the gage section, calculated using the uncracked ligament, was approximately $79 \%$ of the $0.2 \%$ offset yield stress at $649{ }^{\circ} \mathrm{C}$. The final maximum stress level at the gage section, calculated using the uncracked ligament, was nearly $118 \%$ of the $0.2 \%$ offset yield stress. Thus, the FCG behavior in these tests may have been influenced by gross yielding in the gage region. This suggests that the FCG behavior of GXMM247 may be worse than the experimentally-obtained data. Obviously, fatigue crack propagation tests of GXMM247 material using a specimen geometry that meets LEFM criteria would help answer this 
question. Because of the uncertainty in the data, a safety factor of 2 will be used to predict FCG life. This is based on a reasonable engineering assessment.

\section{Limitations With Plastic Zone Size}

The initial and final plane stress plastic zone sizes for both specimens $13 \mathrm{~K}$ and $32 \mathrm{~K}$ using Eq. (9) can be found in Table 3. Ideally, the plastic zone size should carry a number of grain sizes in a material. Due to the relatively coarse grain size of the GXMM247 material, the final plane stress plastic zone size did not exceed the average grain size of $1.6 \mathrm{~mm}$. Thus, the recorded $d a_{c} / d N$ versus $\Delta K$ behavior was likely microstructurally-sensitive [22]. Specifically, grain boundaries may inhibit the crack from growing causing a deceleration in the FCG rate. Alternatively a crack growing within a grain may show an acceleration in the FCG rate.

\begin{tabular}{|c|c|c|}
\hline \multirow{2}{*}{$\begin{array}{l}\text { Specimen, } \\
\mathrm{K}\end{array}$} & \multicolumn{2}{|c|}{ Plane stress plastic zone size } \\
\hline & $\begin{array}{c}\text { Initial, } \\
\mathrm{mm}\end{array}$ & $\begin{array}{c}\text { Final, } \\
\mathrm{mm}\end{array}$ \\
\hline $13 \mathrm{~K}$ & 0.241 & 0.960 \\
\hline $32 \mathrm{~K}$ & 0.230 & 0.902 \\
\hline
\end{tabular}

\section{Fractographic Examination}

An SEM photo of the fracture surface of specimen 13K is shown in SE mode (Figs. 16 and 17). Fracture surface features for $K_{b}$ specimen $32 \mathrm{~K}$ were similar.

Under BE mode, grain boundaries were observed in the fatigue crack propagation region beginning between 0.75 and $1.00 \mathrm{~mm}$ radii from the EDM notch origin (Fig. 18). Note that the $649{ }^{\circ} \mathrm{C} \mathrm{FCG}$ began at approximately $0.82 \mathrm{~mm}$ from the EDM notch origin.

The decreasing crack growth rate at low $\Delta K$ (Fig. 12) at a crack depth between 0.85 and $0.90 \mathrm{~mm}$ may be related to the grain boundary (Fig. 18) between 0.75 and $1.50 \mathrm{~mm}$ from the notch origin. This deceleration in crack growth rate may be due to the crack front encountering a microstructural barrier such as a grain boundary. In fact, the minima in the FCG rate was found to correspond to a crack depth of $0.88 \mathrm{~mm}$ (Fig. 15) for specimen 13K. This is consistent with findings by Taylor [18] and Suresh et al. [20].

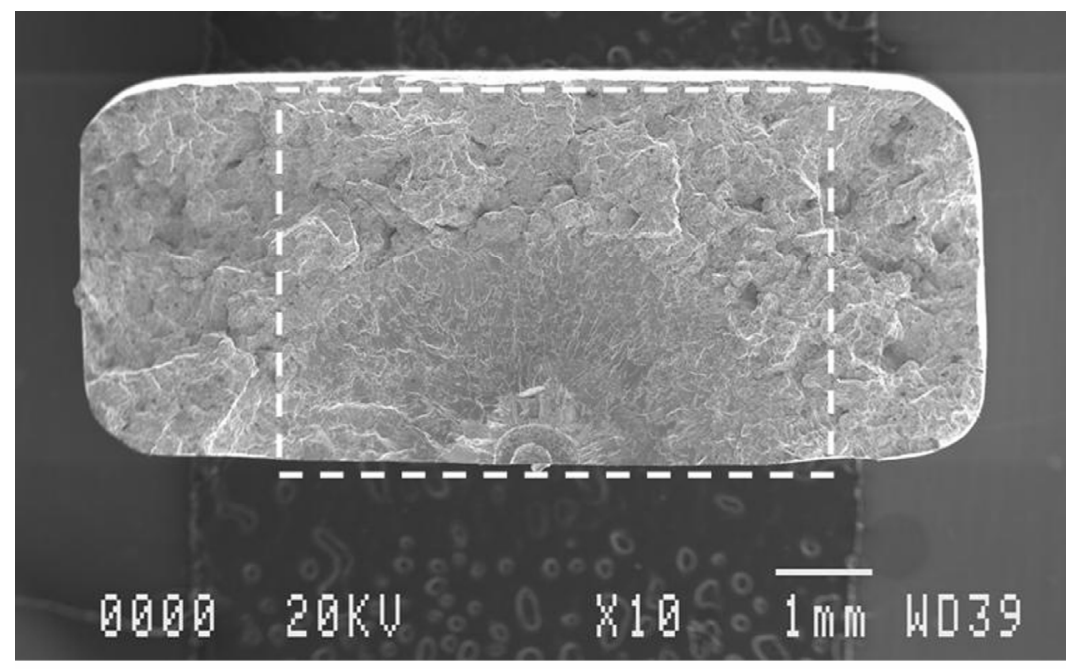

Figure 16.-GXMM247 fatigue crack growth fracture surface for $K_{b}$ specimen $13 \mathrm{~K}$ at $649^{\circ} \mathrm{C}$. Dotted area enlarged in Fig. 17. 


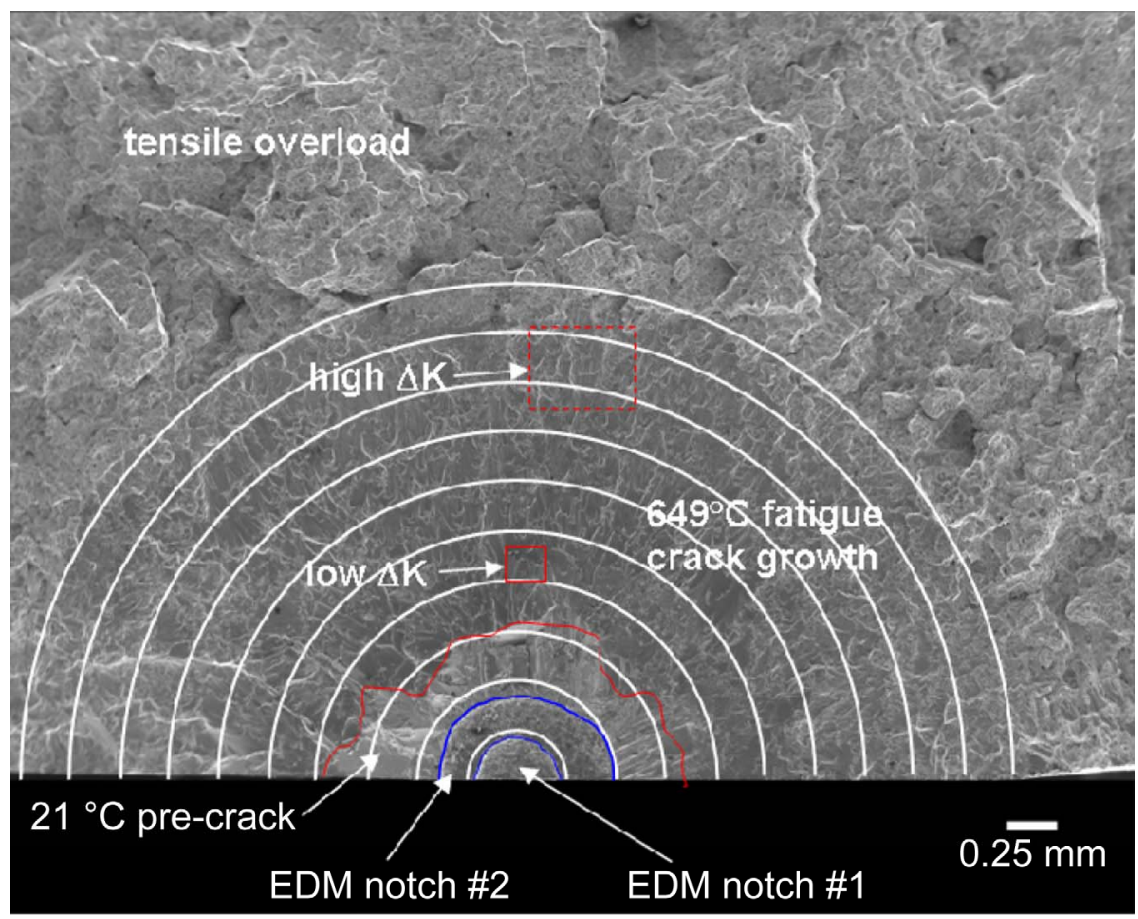

Figure 17.-Close-up of GXMM247 fatigue crack growth fracture surface features for $K_{b}$ specimen $13 \mathrm{~K}$ at $649{ }^{\circ} \mathrm{C}$. Low $\Delta K$ region: 23.3 to $26.4 \mathrm{MPa}$. High $\Delta K$ region: 35.7 to $39.1 \mathrm{MPa}$. SEM (SE Mode). The initial EDM notches are indicated in blue and the initial pre-crack region conducted at $649{ }^{\circ} \mathrm{C}$ is indicated in red.

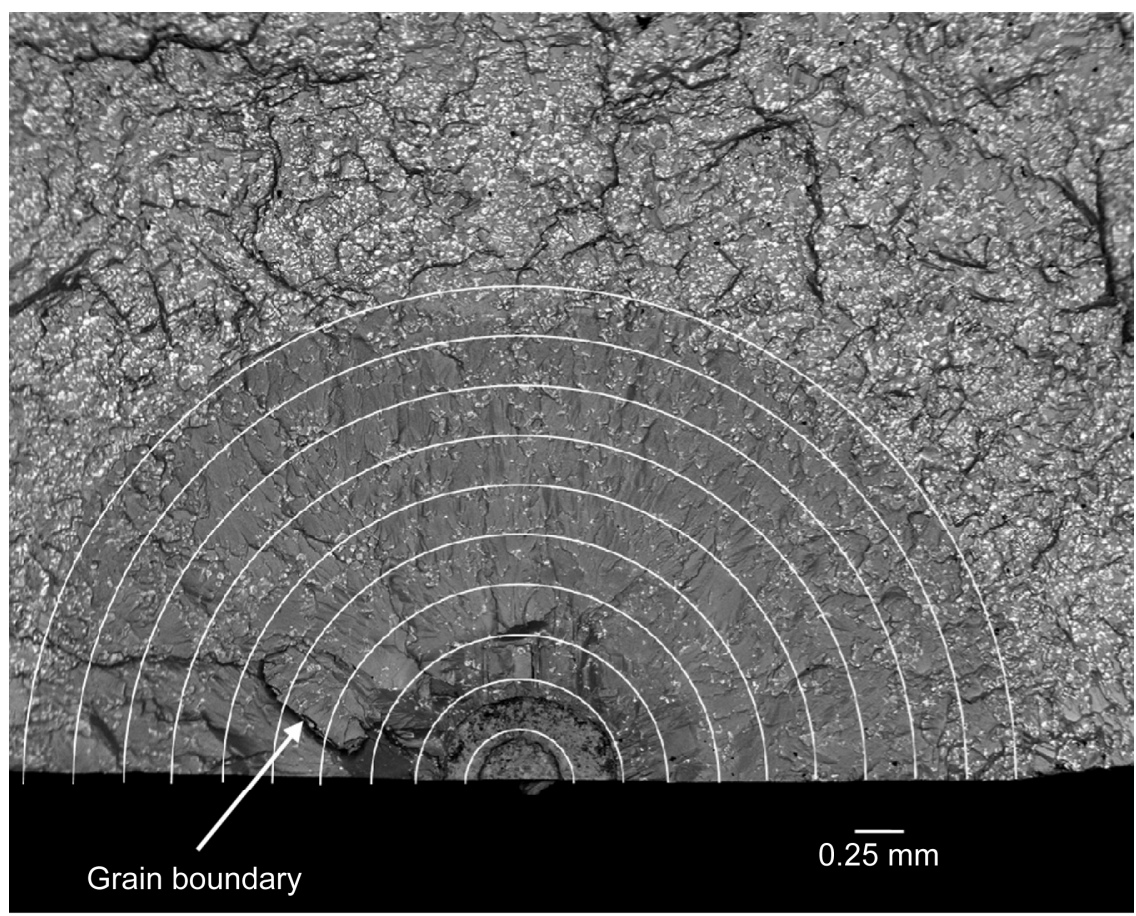

Figure 18.-GXMM247 fatigue crack growth fracture surface for $K_{b}$ specimen $13 \mathrm{~K}$ at $649^{\circ} \mathrm{C}$ showing grain boundary near beginning of fatigue crack growth (SEM BE Mode). 
The low $\Delta K$ region (Fig. 19) of specimen $13 \mathrm{~K}$ between 1.00 to $1.25 \mathrm{~mm}$ from the EDM notch origin showed pockets of fatigue striations. The microstructural FCG rate per cycle was approximately $2.5 \times 10^{-4} \mathrm{~mm} / \mathrm{cycle}$ (Fig. 15). In contrast, the high $\Delta K$ region (Fig. 20) shows more organized and delineated striations and the microstructural FCG rate is approximately $5 \times 10^{-4} \mathrm{~mm} /$ cycle (Fig. 15). Specimen $32 \mathrm{~K}$ showed similar results.

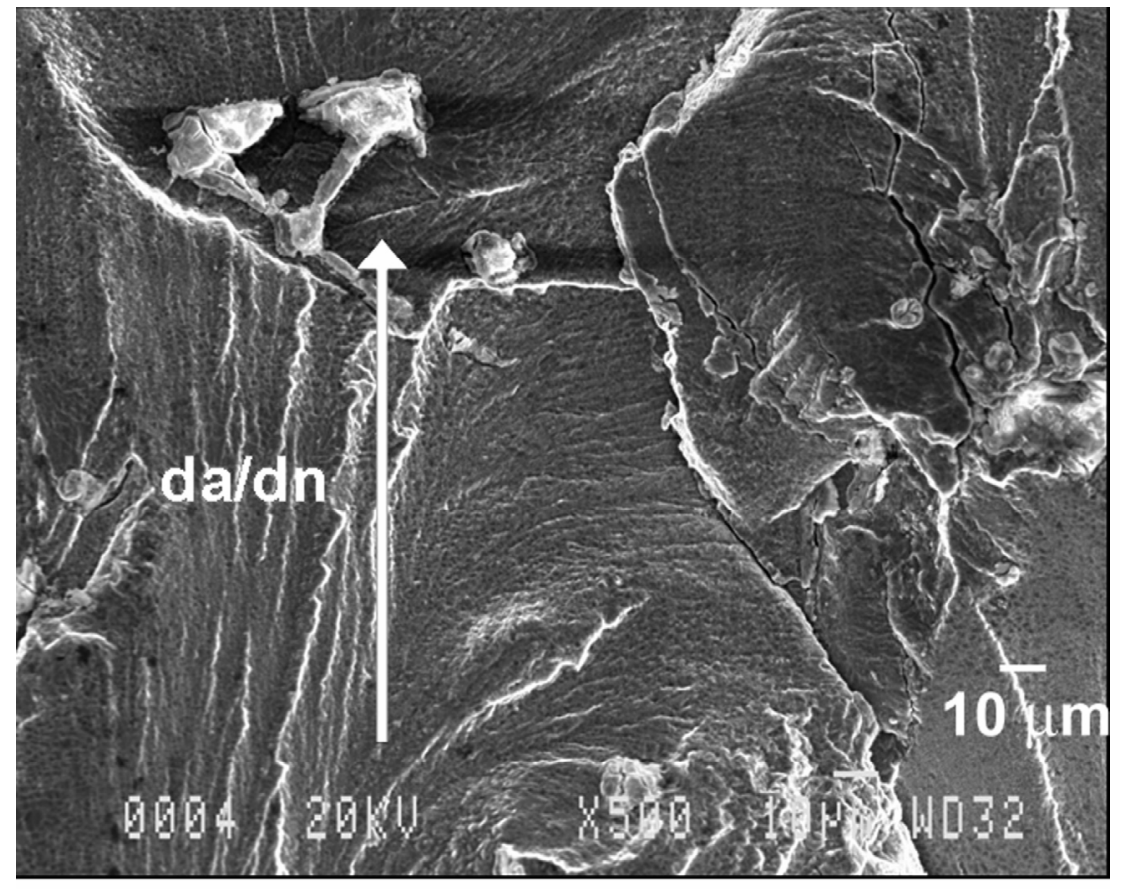

Figure 19.-Low $\Delta K$ fatigue striations of GXMM247 fatigue crack growth fracture surface for $K_{b}$ specimen $13 \mathrm{~K}$ at $649^{\circ} \mathrm{C}$ (SEM SE Mode; see also Fig. 17). $\Delta K$ range from 23.3 to $26.4 \mathrm{MPa}$. Arrow indicates crack growth direction.

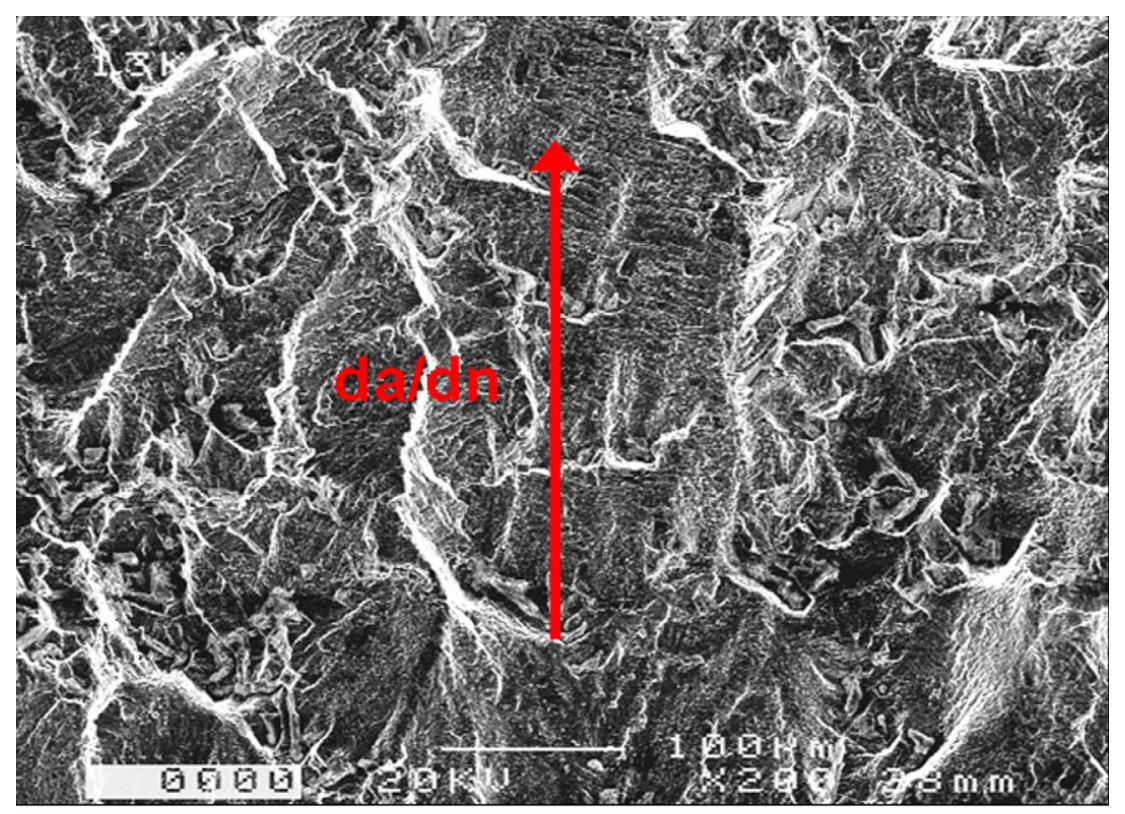

Figure 20.-High $\triangle K$ fatigue striations of GXMM247 fatigue crack growth fracture surface for $K_{b}$ specimen $13 \mathrm{~K}$ at $649^{\circ} \mathrm{C}$ (SEM SE Mode; see also Fig. 17). $\Delta K$ range from 35.7 to $39.1 \mathrm{MPa}$. Arrow indicates crack growth direction. 
Table 4 compares the experimentally applied $\Delta K$ and the calculated $\Delta K$ based on striation spacings taken from the low and high $\Delta K$ regions. The stress intensity ranges were overestimated by the Bates and Clark relationship, Eq. (10), by a factor of 5 for both low and high $\Delta K$ regions.

TABLE 4.-COMPARISON BETWEEN EXPERIMENTAL $\triangle K$ AND CALCULATED $\triangle K$ FROM STRIATION SPACING MEASUREMENTS FOR GXMM247 AT $649{ }^{\circ} \mathrm{C}$.

\begin{tabular}{|c|c|c|c|}
\hline$\Delta K$ Region & $\begin{array}{c}\Delta K \text { (experimental) }{ }^{\mathrm{a}} \\
\mathrm{MPa} \sqrt{m}\end{array}$ & $\begin{array}{c}\text { Striation spacing, } \\
\mathrm{mm} / \mathrm{cycle}\end{array}$ & $\begin{array}{c}\Delta K \text { (Bates \& Clark) [19], } \\
\mathrm{MPa} \sqrt{m}\end{array}$ \\
\hline Low & 24.85 & $2.5 \times 10^{-3}$ & 125.2 \\
\hline High & 37.40 & $5.0 \times 10^{-3}$ & 177.1 \\
\hline
\end{tabular}

${ }^{a}$ Average.

Adjusting Eq. (10) by the percent striated area of the fracture surface may result in better agreement between the experimental and calculated $\Delta K$ [19]. A rigorous survey of the fractographic area would be needed to determine if the Bates and Clark relationship would be a reliable predictor of cyclic stress intensity.

\section{Comparison of Data to Literature}

The regression of the combined experimental data was compared to literature at 426 and $538{ }^{\circ} \mathrm{C}$ (Fig. 21 and Table 5). The FCG rate increases with test temperature at constant cyclic stress-intensity. Data reported by Macha et al. [23], MacIntyre et al. [24], Helmink et al. [25], and Alloy Digest [26] support this observation. The data from this study had the highest FCG rate, since tests were conducted at the highest test temperature, $649^{\circ} \mathrm{C}$.

TABLE 5.-COMPARISON OF EXPERIMENTAL GXMM247 TEST PARAMETERS WITH REPORTED INPUT PARAMETERS FROM AVAILABLE LITERATURE [23-26].

\begin{tabular}{|l|c|c|c|c|c|}
\hline & This study & Macha & MacIntyre & Alloy Digest & Helmink \\
\hline Specimen type & $\mathrm{K}_{\mathrm{b}}$ & $\mathrm{C}-\mathrm{T}$ & Not given & Not given & Not given \\
\hline Temperature, ${ }^{\circ} \mathrm{C}$ & 649 & 426 & 538 & 538 & 538 \\
\hline Frequency, $\mathrm{Hz}$ & 0.33 & 30 & 0.33 & Not given & Not given \\
\hline Load ratio & 0.05 & 0.1 & 0.05 & 0.05 & Not given \\
\hline
\end{tabular}

\section{Determination of the NASA Disk Inspection Interval}

As discussed previously, eddy-current inspections are proposed to examine the NASA disk bolt holes after a set number of cycles at maximum operating conditions in the NASA Seal Rig. A cycle is defined as a ramp up to maximum speed and a ramp down to zero speed at maximum temperature and pressure. In general, jet engine users employ eddy current or other non-destructive inspection techniques at regular intervals to evaluate engine components for excessively long cracks. Eddy current inspection intervals are based on a critical crack length, $a_{\text {crit }}$, from $K_{I C}$ tests at a specific test temperature, stress level, and detectable threshold crack size. As mentioned previously, not enough GXMM247 material was available for a proper $K_{I C}$ test specimen. Alternatively, a surface-flawed specimen was used to characterize the $d a_{c} / d N$ versus $\Delta K$ behavior. By observing the transition from stable crack growth to rapid unstable crack growth behavior, a conservative estimate of the critical crack length at failure can be determined to predict FCG life. Finally, by combining the fatigue strain-life data from previous work by Delgado et al. [1] with the current FCG data, a disk bolt hole eddy-current inspection interval can be calculated. 


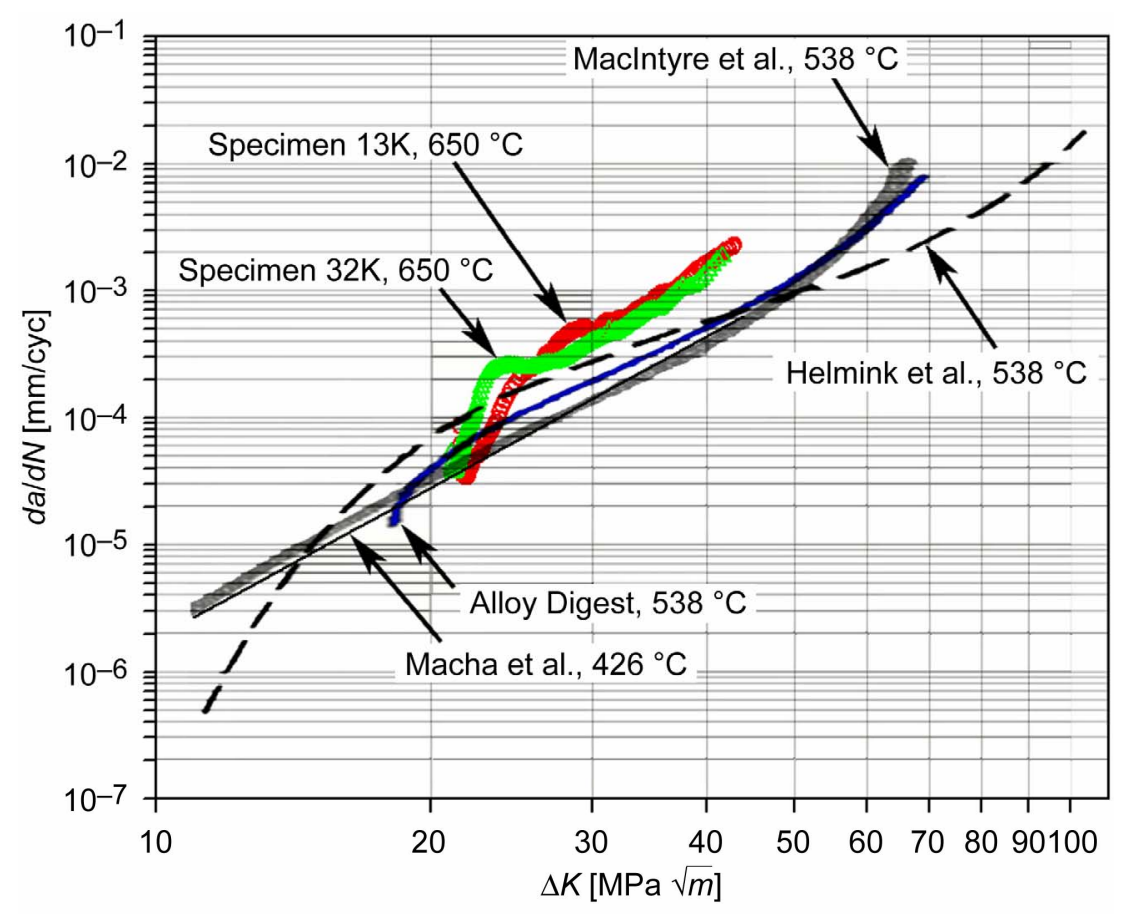

Figure 21.-Comparison of GXMM247 to literature [23-26].

In determining the critical crack length to failure, a comparison of $K_{I C}$ values was first made between experiment and literature. Data reported by Kaufman [27] indicates that the plane-strain fracture toughness, $K_{I C}$, for GXMM247 is greater than $55 \mathrm{MPa} \sqrt{m}$ at $760{ }^{\circ} \mathrm{C}$, Fig. 21 . The maximum $\Delta K$ value of $40.83 \mathrm{MPa} \sqrt{m}$, attained at the end of the FCG tests, can be used as a conservative estimate of $K_{I C}$. This is reasonable since the FCG behavior was observed to be well-behaved at the end of the test (i.e., stable crack growth rate). Assuming $K_{I C}$ to be approximately $40 \mathrm{MPa} \sqrt{m}, a_{\text {crit }}$ is iteratively calculated [28] using an initial crack size of $0.381 \mathrm{~mm}$ (the threshold level for eddy-current inspection [29]) and that the initial crack length, $a_{i}$, occurs at cycle 1 :

1. Calculate $\Delta K$ based on $\Delta K=\hat{F} \Delta \sigma \sqrt{\pi a_{i}} \cdot \Delta \sigma$ is $699 \mathrm{MPa}$ from analyses by Tong and Steinetz [30]. $\hat{F}$ is 1.12 for a half-elliptical surface crack [31].

2. Calculate $d a_{c} / d N$ per Eq. (1) using the values for $C\left(6.34 \times 10^{-12}\right)$ and $m(5.28)$ found for the combined data set (Fig. 14).

3. Recalculate the crack length for cycle 2 by adding the previous crack length, $a_{i}$, to the value $d a_{c} / d N$ calculated in step 2 . The estimated crack growth length for the following cycle is $d a_{c} / d N$.

4. Repeat steps 1 to 3 until $\Delta K$ is approximately $40 \mathrm{MPa} \sqrt{m}$.

The resultant critical crack length is $0.831 \mathrm{~mm}$ at 734 cycles for $\Delta K=40 \mathrm{MPa} \sqrt{m}$, (Fig. 22). An average crack growth of $0.016 \mathrm{~mm}$ per 50 cycles is calculated from cycle 0 to approximately cycle 350 . Recall that an arbitrary safety factor of 2 on cyclic FCG life was used since FCG results indicate that LEFM conditions were not met and gross yielding was predicted at the gage section. Thus, the calculated cyclic life of 734 cycles is reduced, by half, to 367 cycles. Also, the corresponding crack depth is reduced from $0.831 \mathrm{~mm}$ to a crack depth of $0.501 \mathrm{~mm}$. 


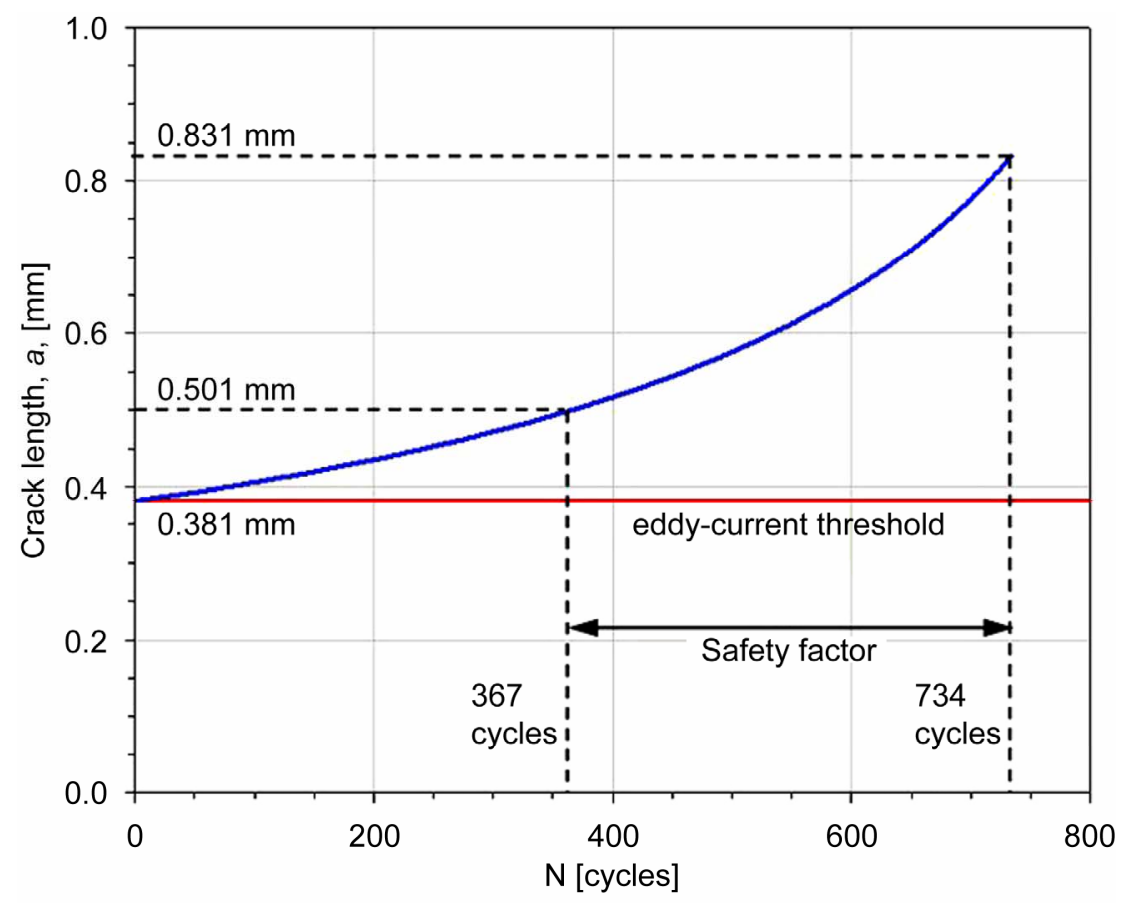

Figure 22.-GXMM247 NASA disk fatigue crack growth rate with increasing cycles at $649^{\circ} \mathrm{C}$.

The total fatigue life of a material often encompasses approximately $90 \%$ fatigue strain-life and $10 \%$ FCG life [32]. Given the $R_{\varepsilon}=0$ fatigue strain-life crack initiation curve at $649{ }^{\circ} \mathrm{C}$ at the design strain of $0.5 \%$ from Delgado and others [1], the mean life to crack initiation is approximately 15,000 cycles. Combining this with the predicted fatigue crack propagation cycles to failure, 734, in Fig. 22 gives a total life of 15,734 cycles. This approach suggests that, for the GXMM 247 NASA disk operating at $649{ }^{\circ} \mathrm{C}$ metal temperature, crack initiation represents $95 \%$ of the cyclic life of the NASA disk while the remaining $5 \%$ is used to propagate the crack to failure.

However, considering the environment in which the NASA disk is used and the safety required for personnel and equipment, statistical and other safety factors must be used to estimate the inspection interval. Specifically, using the $-99.95 \%$ prediction given by Delgado and others [1], the cyclic life to crack initiation, with statistically 1 failure in 2000, is 1100 cycles at the design strain of $0.5 \%$ at $649{ }^{\circ} \mathrm{C}$. Accounting for the 6 bolt holes using the system life analysis, the resultant crack initiation life is 665 cycles [1]. Combining this with the predicted fatigue crack propagation result on life of 367 cycles (using a factor of safety of 2) gives a total cyclic life for the GXMM247 NASA disk bolt holes of 1032 cycles at a crack length of $0.501 \mathrm{~mm}$ at maximum disk operating conditions. Since the eddy-current detection threshold is currently $0.381 \mathrm{~mm}$, an initial NASA disk bolt hole inspection is recommended starting at approximately 665 cycles to detect crack initiation. Inspection intervals are then recommended approximately every 50 cycles thereafter to adequately monitor FCG. The NASA disk should be retired from high temperature service upon attaining either 1032 cycles or a crack depth of $0.501 \mathrm{~mm}$ (Fig. 23). One possible implementation plan is given in Fig. 24. 


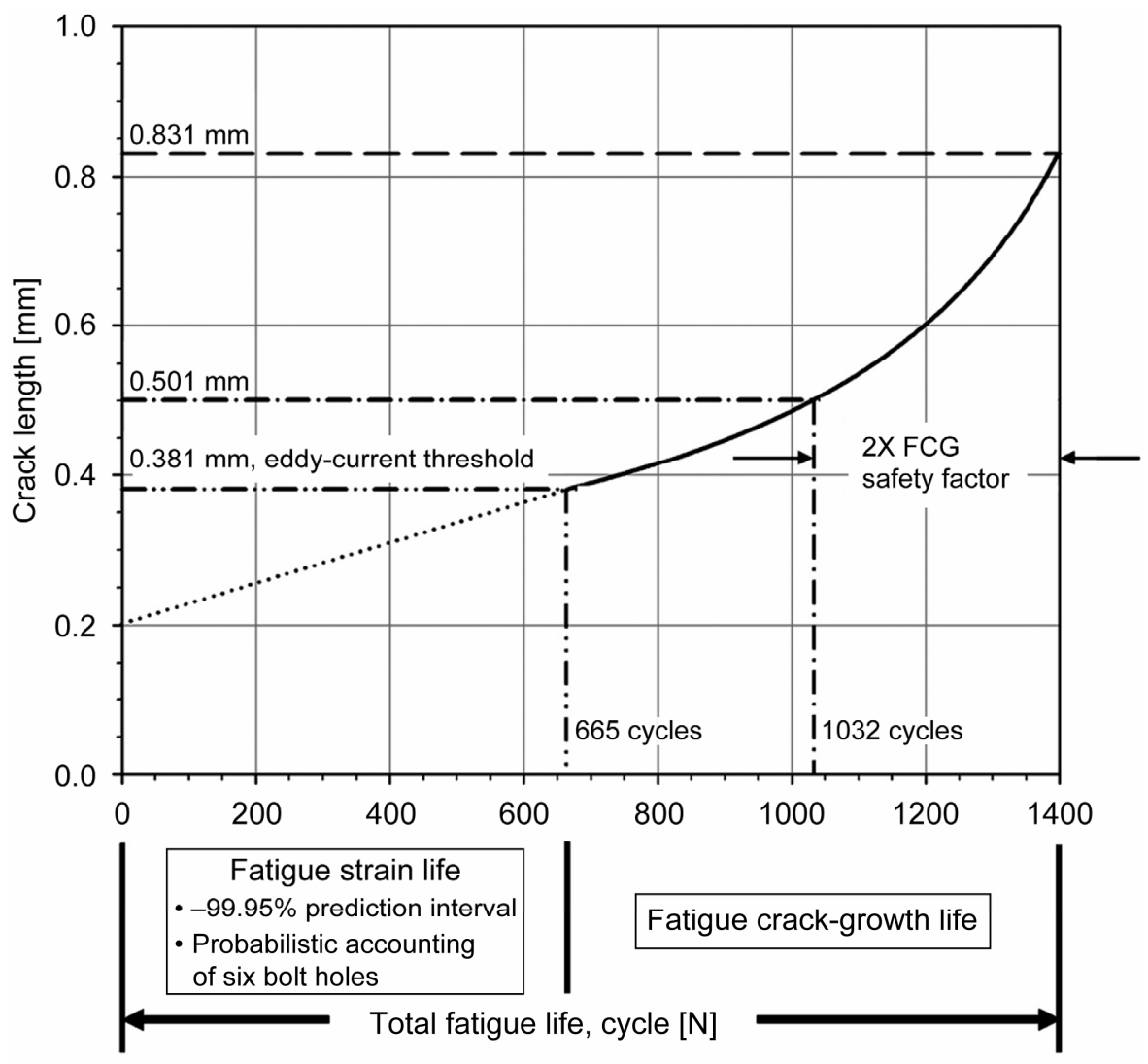

Figure 23.-Total fatigue life of GXMM247 at maximum operating conditions of the NASA turbine seal test rig.

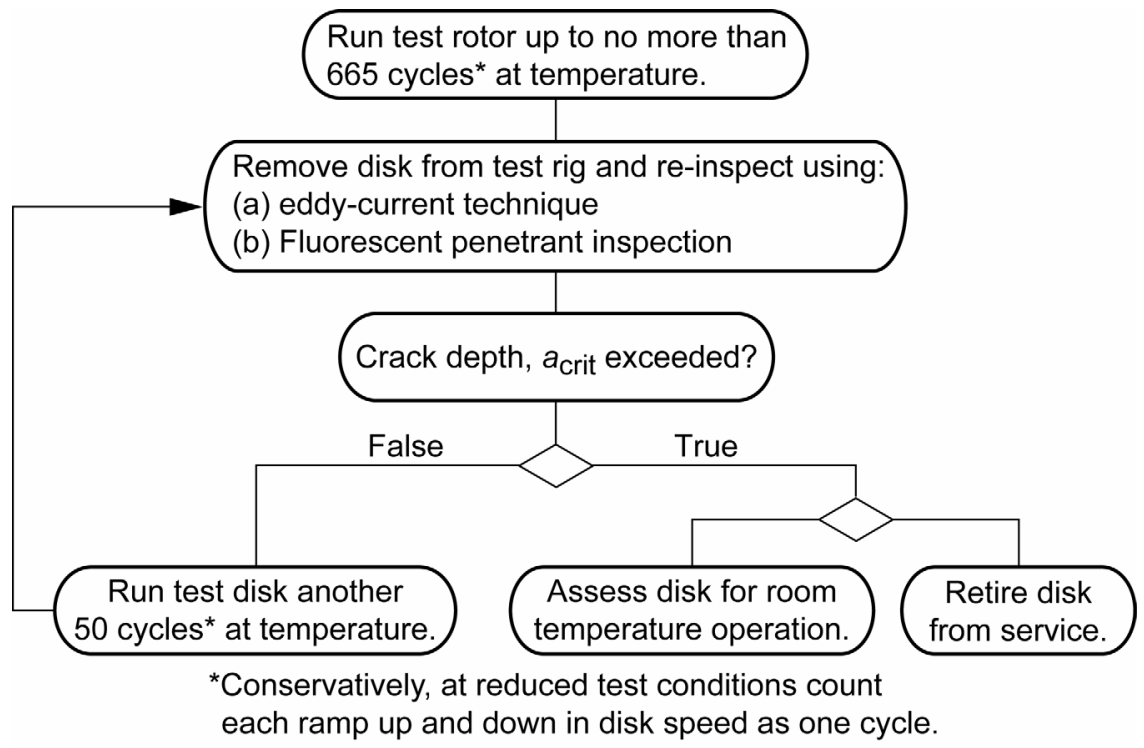

Figure 24.-Decision flow chart for implementing eddy-current inspection interval for GXMM247 NASA disk. 
A limitation to this study was that there was a lack of sufficient material from which to make the FCG specimens; this largely contributed to the breakdown of the LEFM model. One way to examine the data is to use an elastic-plastic fracture mechanics approach. However, such an analysis was beyond the scope of this study. Also, it is acknowledged that short crack growth behavior is characterized by higher crack growth rates when compared to long crack growth behavior. Also, grain size, crystallographic orientation, and grain boundaries influence short crack growth behavior. However, modeling the short-crack growth behavior of GXMM247 was beyond the scope of this effort.

In light of these limitations, and to summarize, a number of conservative measures were taken to preclude disk failure in the test facility:

1. Two FCG specimen data sets were statistically combined to provide better characterization of the FCG behavior of GXMM247.

2. A conservative value of $40 \mathrm{MPa} \sqrt{m}$ was chosen for the critical crack growth rate. A comparison to available literature (Fig. 21) shows that the actual value is likely to be greater than $40 \mathrm{MPa} \sqrt{m}$.

3. A safety factor of 2 was placed on the cycles to failure for the disk due to the breakdown of LEFM.

4. The disk will be inspected after approximately 665 cycles based on previous strain-life analyses by the authors [1].

\section{Summary}

An eddy current inspection interval is proposed for detecting cracks in the bolt hole surfaces of the GXMM247 disk used in NASA's High Temperature, High-Speed Turbine Seal Test Rig. Cracks may initiate and grow in the bolt holes due to cyclic stresses from seal tests at high temperature, pressure, and surface speeds. The inspection interval is based upon previous fatigue strain-life data and current fatigue crack growth data resulting from tests using specimens fabricated from a sacrificial GXMM247 disk. Since not enough material was available for a proper $K_{I C}$ test, surface-flawed specimens were fabricated and tested to characterize the $d a_{d} / d N$ versus $\Delta K$ behavior of the material at maximum rig operating conditions. Data sets from successful fatigue crack growth tests were fitted to a Paris type relationship and then statistically combined.

Small crack growth behavior was observed by minima in the fatigue crack growth rate and is likely due to microstructural barriers such as grain boundaries. Also, microstructurally-sensitive behavior is likely because the final plane stress plastic zone size was predicted to be smaller than the average grain size. However, the fatigue crack growth behavior transitioned towards long crack growth behavior at higher $\Delta K$. Also, gross yielding at the fracture surfaces indicated a more severe $d a_{c} / d N$ versus $\Delta K$ behavior than given by the data. Thus, LEFM criteria were not met and an arbitrary factor of 2 safety was used for determining fatigue crack growth life. To predict the critical cycles to failure a conservative estimate of $40 \mathrm{MPa} \sqrt{m}$ was obtained for the critical crack growth rate after comparing the data to literature.

Using an iterative approach, critical fatigue crack propagation is predicted at 367 cycles at a crack depth of $0.501 \mathrm{~mm}$ using a safety factor of 2 on life. Combining this with previous fatigue strain-life experimental work gives a critical crack life of 1032 cycles at a crack length of $0.501 \mathrm{~mm}$ at maximum operating conditions. Eddy-current inspections are suggested starting at 665 cycles since eddy current thresholds are currently at $0.381 \mathrm{~mm}$. Inspection intervals are recommended every 50 cycles at maximum operating conditions. Improvements on the fatigue crack growth life can be improved using valid $K_{I C}$ tests. 


\section{References}

1. Delgado, I. R., Halford, G. R., Steinetz, B. M., and Rimnac C. M., 2005, "Strain-Life Assessment of Grainex Mar-M 247 for NASA's Turbine Seal Test Facility," Journal of Engineering for Gas Turbines and Power, 127, pp. 615-620.

2. Coles, A., Johnson, R.E., and Popp, H.G., 1976, "Utility of Surface-Flawed Tensile Bars in Cyclic Life Studies," Journal of Engineering Materials and Technology, 98, pp. 305-315.

3. Diez, A., 2000, "Crack formation in bolt holes," personal communication by Irebert Delgado.

4. Hartman, G.A., and Ashbaugh, N.E., 1990, "A Fracture Mechanics Test Automation System for a Basic Research Laboratory," Applications of Automation Technology to Fatigue and Fracture Testing, ASTM STP 1092, A.A. Braun, N.E. Ashbaugh, and F. M. Smith, eds., ASTM, Philadelphia, pp. $95-110$.

5. Ashbaugh, N. and Hartman, G., 1990, "Direct Current Electric Potential Workshop," MATE Workshop, University of Dayton Research Institute.

6. Gangloff, R. P., Slavik, D. C., Piascik, R. S., and Van Stone, R. H., 1992, "Direct Current Electrical Potential Measurement of the Growth of Small Cracks," Small-Crack Test Methods, ASTM STP 1149, Larsen, J. M., and J.E. Allison eds., ASTM, Philadelphia, pp. 116-168.

7. Hartman, G., 2002, "Questions on MATE program," personal communication by Irebert Delgado.

8. Gangloff, R. P., 1981, "Electric Potential Monitoring of Crack Formation and Subcritical Growth from Small Defects," Fatigue of Engineering Materials and Structures, 4.1, pp. 15-33.

9. VanStone, R. H., and Richardson, T. L., 1985, "Potential-Drop Monitoring of Cracks in SurfaceFlawed Specimens," Automated Test Methods for Fracture and Fatigue Crack Growth, ASTM STP 877, W.H. Cullen, , R.W. Landgraf, L.R. Kaisand, and J.H. Underwood, eds., ASTM Philadelphia, PA, pp. 148-166.

10. Shannon, B., 2000, “Accounting for thermoelectric influences," personal communication by Irebert Delgado.

11. Shannon, B., 2003, "FCG data acquisition rate," personal communication by Irebert Delgado.

12. Telesman, J., 2002, "Crack growth limitations," personal communication by Irebert Delgado.

13. Newman, J. C., Jr., and Raju, I. S., 1983, "Stress-Intensity Factor Equations for Cracks in ThreeDimensional Finite Bodies," Fracture Mechanics: Fourteenth Symposium-Volume I: Theory and Analysis, ASTM STP 791, J.C. Lewis and G. Sines, eds., ASTM, Philadelphia, PA, pp. I-238 - I-265.

14. ASTM Committee E-8 on Fatigue and Fracture, 1998, "ASTM E-647-95a Standard Test Method for Measurement of Fatigue Crack Growth Rates." Annual Book of ASTM Standards 2001, Section 3 Metals Test Methods and Analytical Procedures, Volume 03.01 Metals-Mechanical Testing; Elevated and Low-Temperature Tests, Metallography, ASTM. West Conshohocken, pp. 577-613.

15. Dowling, N. E., 1999, Mechanical Behavior of Materials: Engineering Methods for Deformation, Fracture, and Fatigue, Prentice-Hall, Inc., Upper Saddle River.

16. Neter, J., and Wasserman. W., 1974, Applied Linear Statistical Models, Richard D. Irwin, Inc., Homewood.

17. Howmet Turbine Components Corporation. TB 3000: Grainex Cast Mar-M 247 Alloy, Howmet Turbine Components Corporation, Greenwich.

18. Taylor, D., 1989, Fatigue Thresholds, Butterworths, London.

19. Bates, R. C., and Clark, W. G., Jr., 1969, "Fractography and Fracture Mechanics," ASM Transactions Quarterly, 62.2, pp. 380-389.

20. Suresh, S., and Ritchie, R. O. "Propagation of short fatigue cracks." International Metals Reviews. 29.6 (1984) pp.445-476.

21. Taylor, D., 1985, A Compendium of Fatigue Thresholds and Growth Rates, Chameleon Press LTD, London.

22. Hertzberg, R. W., 1989, Deformation and Fracture Mechanics of Engineering Materials, 3rd ed., John Wiley and Sons, Inc., New York. 
23. Macha, D. E., Cole, G. R., and Butzer, J. A., 1983, "Fine Grain, Investment-Cast Integral Turbine Wheels," Grain Refinement in Castings and Welds, G. J. Abbaschian and S. A. David, eds., The Metallurgical Society of AIME, New York, pp. 197-219.

24. MacIntyre, C. A., and Agarwal, P. N., 1984, "Development of Fine Grain Cast Mar-M 247 Axial and Radial Turbine Wheels," Advanced Aerospace Materials Technology, SP-597, Society of Automotive Engineers, Inc., Warrendale, pp. 35-45.

25. Helmink, R.C. et al., 2000, "Advanced Superalloys and Tailored Microstructures for Integrally Cast Turbine Wheels,” Superalloys 2000, T. M. Pollock et al., eds., TMS, Warrendale, pp. 171-179.

26. "Microcast-X Mar-M 247." Alloy Digest, May 1995.

27. Kaufman, M., 1984, "Properties of Cast Mar-M-247 for Turbine Blisk Applications," Superalloys 1984, Maurice Gell et al. eds., Metallurgical Society of AIME, Warrendale, pp. 43-52.

28. Broek, D., 1984, Elementary Engineering Fracture Mechanics, 3rd ed., Kluwer Boston, Inc., Hingham.

29. Curtis Industries, Inc., 2003, "Reference Standard Calibration for GX Mar-M 247," inspection report for reference standard, Curtis Industries, Inc., Pennsylvania.

30. Tong, M., and Steinetz, B., 1997, "Mar-M 247 Disk Finite Element Thermal and Stress Analysis", NASA Glenn Research Center, Cleveland.

31. Dowling, N. E., 1999, Mechanical Behavior of Materials: Engineering Methods for Deformation, Fracture, and Fatigue, Upper Saddle River, Prentice-Hall, Inc.

32. Kerlins, V., and Phillips, A., 1987, "Modes of Fracture," Metals Handbook, Volume 12 Fractography, 9th ed., ASM International, Metals Park. 


\section{Appendix-Symbols}

C

E

$\hat{F}$

$F^{*}$

FCG

$F_{s}$

GXMM247

$K_{I}$

$K_{I C}$

$K_{\max }$

$L_{p}$

$P$ or $P_{\max }$

$Q$

$R$

$R_{\varepsilon}$

$\operatorname{SSE}(F)$

$\operatorname{SSE}(R)$

V

V

$V_{N}$

$X_{i j}$

$Y_{i j}$

$a_{c}$

$a_{i}$

$a_{n}$

$b_{c}$

$b_{n}$

$c_{c}$

$c_{n}$

$d a_{c} / d N$

$h$

$m$

$n_{1}$

$n_{2}$

$s$ fatigue crack growth coefficient $\left[\frac{\mathrm{mm} / \text { cycle }}{(\mathrm{MPa} \sqrt{m})^{m}}\right]$

Young's Modulus

dimensionless geometry factor

test statistic for linear test

fatigue crack growth

boundary correction factor

Grainex Mar-M 247

stress-intensity factor (Mode I) [MPa $\sqrt{m}]$

Mode I critical fracture toughness [MPa $\sqrt{m}$ ]

maximum stress intensity factor [MPa $\sqrt{m}$ ]

potential probe spacing half-width [mm]

fatigue crack growth load [KN]

shape factor

stress ratio

strain ratio $=\varepsilon_{\min } / \varepsilon_{\max }$

sum squared error of full model

sum squared error of reduced model

crack length voltage [volts]

crack length voltage [volts]

reference voltage [volts]

statistical model independent variable

statistical model predicted value

crack depth [mm]

iterative crack length [mm]

initial EDM crack depth [mm]

crack half-height [mm]

initial crack half-height [mm]

crack surface half-width [mm]

initial crack surface half-width [mm]

fatigue crack growth rate [mm/cycle]

half-height of the $K_{b}$ specimen gage section from the EDM notch [mm]

fatigue crack growth exponent

number of data points for data set 1

number of data points for data set 2

remote uniform tensile stress [MPa] 


$\begin{array}{ll}t & \text { through thickness of test specimen }[\mathrm{mm}] \\ \Delta K & \text { stress intensity range [MPa } \sqrt{m}] \\ \Delta K_{\mathrm{th}} & \text { threshold stress intensity range }[\mathrm{MPa} \sqrt{m}] \\ \Delta \sigma & \text { stress range [MPa] } \\ \beta_{0} & \text { intercept of reduced model } \\ \beta_{1} & \text { slope of reduced model } \\ \varepsilon_{i j} & \text { statistical model error term } \\ \phi & \text { ellipse parametric angle [radians] }\end{array}$




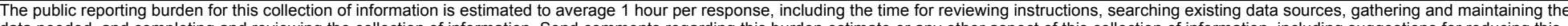

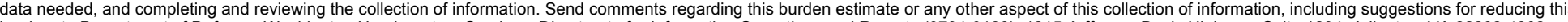

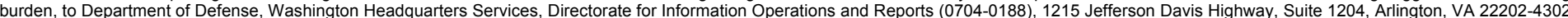

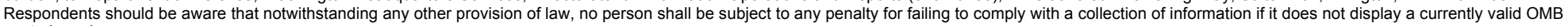
control number.

PLEASE DO NOT RETURN YOUR FORM TO THE ABOVE ADDRESS.

\section{REPORT DATE (DD-MM-YYYY) \\ 2. REPORT TYPE \\ 3. DATES COVERED (From - To)}

01-08-2008

\section{TITLE AND SUBTITLE}

Technical Memorandum

Fatigue Crack Growth Behavior Evaluation of Grainex Mar-M 247 for NASA's High

Temperature, High Speed Turbine Seal Test Rig

\section{5a. CONTRACT NUMBER}

5b. GRANT NUMBER

5c. PROGRAM ELEMENT NUMBER

6. AUTHOR(S)

Delgado, Irebert, R.; Steinetz, Bruce, M.; Rimnac, Clare, M.; Lewandowski, John, J.

\section{5d. PROJECT NUMBER}

5e. TASK NUMBER

5f. WORK UNIT NUMBER

WBS 561581.02.08.03.15.02

8. PERFORMING ORGANIZATION REPORT NUMBER

E-16529-1

National Aeronautics and Space Administration

John H. Glenn Research Center at Lewis Field

Cleveland, Ohio 44135-3191

\section{SPONSORING/MONITORING AGENCY NAME(S) AND ADDRESS(ES)}

National Aeronautics and Space Administration

Washington, DC 20546-0001

\section{SPONSORING/MONITORS ACRONYM(S) \\ NASA \\ 11. SPONSORING/MONITORING REPORT NUMBER \\ NASA/TM-2008-215287}

\section{DISTRIBUTION/AVAILABILITY STATEMENT}

Unclassified-Unlimited

Subject Category: 37

Available electronically at http://gltrs.grc.nasa.gov

This publication is available from the NASA Center for AeroSpace Information, 301-621-0390

\section{SUPPLEMENTARY NOTES}

\section{ABSTRACT}

The fatigue crack growth behavior of Grainex Mar-M 247 is evaluated for NASA's Turbine Seal Test Facility. The facility is used to test air-to-air seals primarily for use in advanced jet engine applications. Because of extreme seal test conditions of temperature, pressure, and surface speeds, surface cracks may develop over time in the disk bolt holes. An inspection interval is developed to preclude catastrophic disk failure by using experimental fatigue crack growth data. By combining current fatigue crack growth results with previous fatigue strain-life experimental work, an inspection interval is determined for the test disk. The fatigue crack growth life of the NASA disk bolt holes is found to be 367 cycles at a crack depth of $0.501 \mathrm{~mm}$ using a factor of 2 on life at maximum operating conditions. Combining this result with previous fatigue strain-life experimental work gives a total fatigue life of 1032 cycles at a crack depth of $0.501 \mathrm{~mm}$. Eddy-current inspections are suggested starting at 665 cycles since eddy current detection thresholds are currently at $0.381 \mathrm{~mm}$. Inspection intervals are recommended every 50 cycles when operated at maximum operating conditions.

\section{SUBJECT TERMS}

Fatigue; Crack growth; Mar-M 247

\begin{tabular}{|c|c|c|c|c|}
\hline 16. SECURI & ASSIFICATION & & 17. LIMITATION OF & 18. NUMBER \\
\hline $\begin{array}{l}\text { a. REPORT } \\
\text { U }\end{array}$ & $\begin{array}{l}\text { b. ABSTRACT } \\
\text { U }\end{array}$ & $\begin{array}{l}\text { c. THIS } \\
\text { PAGE } \\
\text { U }\end{array}$ & UU & $\begin{array}{c}\text { PAGES } \\
32\end{array}$ \\
\hline
\end{tabular}

19a. NAME OF RESPONSIBLE PERSON STI Help Desk (email:help@sti.nasa.gov) 19b. TELEPHONE NUMBER (include area code) $301-621-0390$ 

